UCRL-ID-131282

\title{
Bigplate: An Oblique Angle Explosive EOS Test
}

\author{
P. Clark Souers \\ Steve Anderson \\ Rex Avara \\ Larry Fried \\ Jim Janzen \\ Stella McGuire \\ Ben Wu
}

April 16, 1998

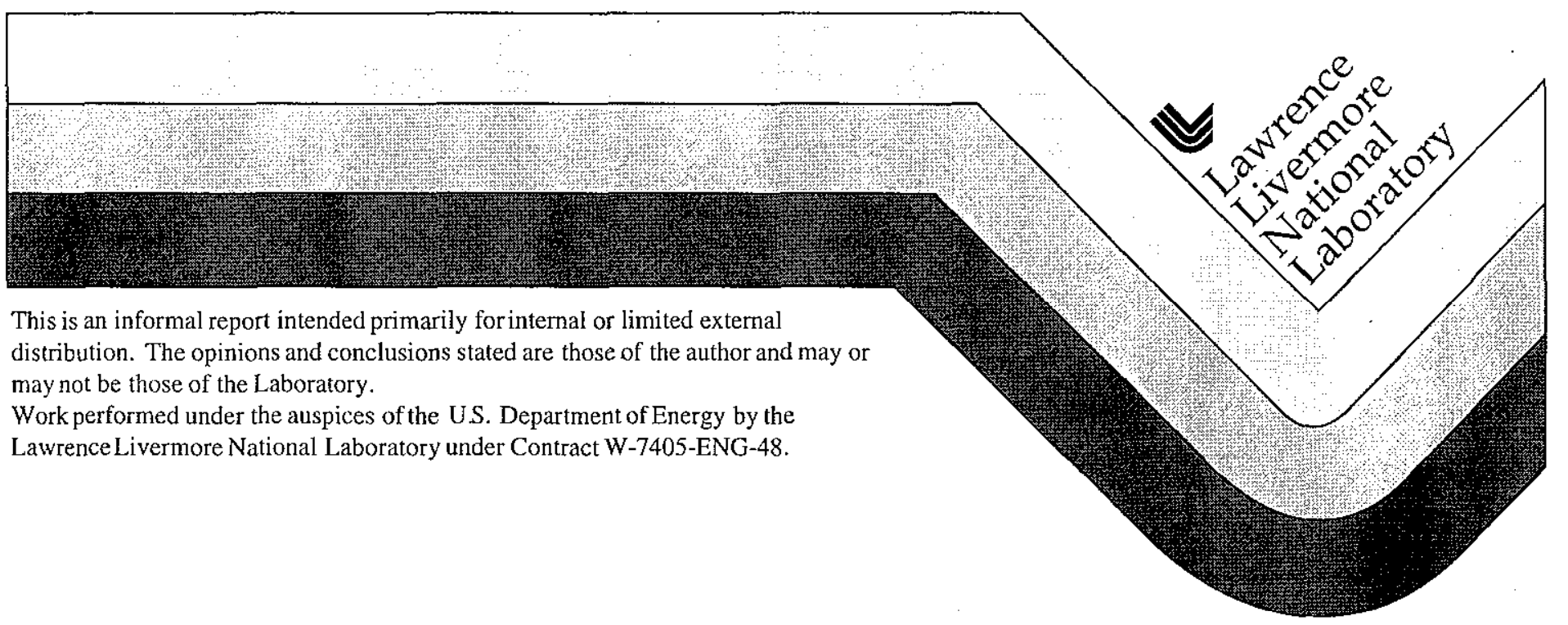




\section{DISCLAIMER}

This document was prepared as an account of work sponsored by an agency of the United States Government. Neither the United States Government nor the University of California nor any of their employees, makes any warranty, express or implied, or assumes any legal liability or responsibility for the accuracy, completeness, or usefulness of any information, apparatus, product, or process disclosed, or represents that its use would not infringe privately owned rights. Reference herein to any specific commercial product, process, or service by trade name, trademark, manufacturer, or otherwise, does not necessarily constitute or imply its endorsement, recommendation, or favoring by the United States Government or the University of California. The views and opinions of authors expressed herein do not necessarily state or reflect those of the United States Government or the University of California, and shall not be used for advertising or product endorsement purposes.

This report has been reproduced directly from the best available copy.

Available to DOE and DOE contractors from the Office of Scientific and Technical Information

P.O. Box 62, Oak Ridge, TN 37831

Prices available from (615) 576-8401, FTS 626-8401

Available to the public from the

National Technical Information Service

U.S. Department of Commerce

5285 Port Royal Rd.,

Springfield, VA 22161 


\title{
Bigplate: An Oblique Angle Explosive EOS Test (U)
}

\author{
text:U
}

P. Clark Souers, Steve Anderson, Rex Avara, Larry Fried, Jim Janzen, Stella McGuire and Ben Wu

Report on Project TTL-16 in the Enhanced Surveillance Program Jeff Kass, LLNL Program Manager

Lawrence Livermore National Laboratory

Livermore, CA, USA 94550

April 16, 1998

URCL- 


\title{
Table of Contents
}

\section{Chapter 1. Introduction}

1. What Bigplate is

2. Defined Explosive Kinetics

\section{Chapter 2. Sensitivity Analysis}

1. Small Error: Explosive Density

2. Large Error: Plate Thickness

3. Small Error: Fabry Allignment

4. Medium Error: Fabry Velocity

5. Large Error: Fabry Timing

6. Large Error: Jump-Off Time at $80 \mathrm{~mm}$

7. Large Error: Spall Timing

8. Summary

\section{Chapter 3. Data and Analysis}

1. Basic Data

2. Code Modeling of Spall

3. Spall Summary

4. The Jump-Off Discrepancy

5. Code Comparisons for the Explosive EOS

6. Comparison of Explosives

7. CHEETAH

\section{Chapter 4. Conclusions}

1. Bigplate as an EOS Test

2. EOS Testing

3. Volume of the Test

4. Final Note

\begin{abstract}
Bigplate is an advanced explosive equation of state (EOS) test. It consists of a point detonator driving a large disc (100 mm radius) of explosive, which pushes a $0.5 \mathrm{~mm}$ thick copper or tantalum plate. The plate is observed by a five-beam Fabry-Perot interferometer, which has beams at $0,10,20,40$ and $80 \mathrm{~mm}$ on the plate. A short Fabry gives the jump-off to high accuracy; a long Fabry runs out to 10-15 $\mu$ s. A detailed error analysis is given, with the final velocity measurments considered good to $\pm 0.066 \mathrm{~mm} / \mu \mathrm{s}$. Jump-offs are measured to 0.01-0.02 $\mu$ s. Spall is seen in all shots, which creates a time delay on both the first and second velocity plateaus. A $0.1 \mu$ s delay in jump-off of unknown origin is also seen at $80 \mathrm{~mm}$. In order of decreasing explosive ideality, the explosives fired have been LX-14, LX -04 and LX-17. To partially negate the time delays, the data and code runs are overlaid at each radial position between the first and second plateaus. Traditional JWL's model LX-14 and LX-04 within accuracy, but not so for LX-17. The spall may be partly modeled using the pmin model but high resolution zoning is required. At longer times, spall does not appear to affect the explosive energetics. Because it includes diagonal zone crossing, Bigplate occupies a location between simple plate and cylinder tests and truly complex geometries. Hence, an EOS that fails Bigplate is not likely to move on to more complex issues. Bigplate is an excellent testbed for radically new EOS's, and the initial LX-17 runs done with Equilibrium and KINETIC CHEETAH are promising.
\end{abstract}




\section{Chapter 1. Introduction}

\section{What Bigplate is}

Bigplate is a unique explosive equationof-state (EOS) test in that variable angles of incidence exist between the explosive and the metal being pushed. Figure 1 (end of the chapter) shows a picture and Figure 2 the sideview schematic for Bigplate. A disk of explosive is pressed with a radius of $100 \mathrm{~mm}$. The explosives are LX-14 (95.5\% HMX, 4.5\% estane), LX-04 (85\% HMX, 15\% Viton-A, and LX-17 (92.5\% TATB, $7.5 \%$ Kel-F). The disk thickness is 20 $\mathrm{mm}$ for LX-04 and LX-14 and $40 \mathrm{~mm}$ for LX-17. A $0.5 \mathrm{~mm}$ oxygen-free copper plate is glued to one side of the explosive, and a point detonator is placed on the axis at the back. A hole is dug out so that the detonator is flush with the back. There is no support plate on the back. The LX17 parts also have an ultrafine TATB hemisphere booster of $19 \mathrm{~mm}$ radius. One LX-04 shot was done with a $0.5 \mathrm{~mm}$ thick tantalum plate.

\section{A billet of explosive is pressed to 216} $\mathrm{mm}$ diameter and $152 \mathrm{~mm}$ thick. It is then cut in half to make two parts and each part is machined to final tolerances. The $0.5 \mathrm{~mm}$-thick copper plate is annealed at $375^{\circ} \mathrm{C}$ for 30 minutes in a vacuum; then it is machined on a lathe to final tolerances. The machining is done to create a non-directional grain orientation. Lines are drawn onto the plate every $15 \mathrm{~mm}$ to show possible plate movement. The metal plate is glued to the front side of the explosive with estane. A creep fixture holds the metal to the explosive at 100 psi and $40^{\circ} \mathrm{C}$ for 8 hours. A 0.2 $\mathrm{mm}$ bow appears across the center of the plate as a result.. The actual Bigplate sits vertically in an aluminum holder with a $7.5 \mathrm{~mm}$ thick bracket running around the top half. The aluminum runs straight downward from the right and left edges so that a solid aluminum plate runs from the bottom of the explosive to the floor plate. The overall geometry is 3-D if the aluminum is considered. A $7.5 \mathrm{~mm}$ aluminum rim was included in the 2-D code to simulate the edge containment.

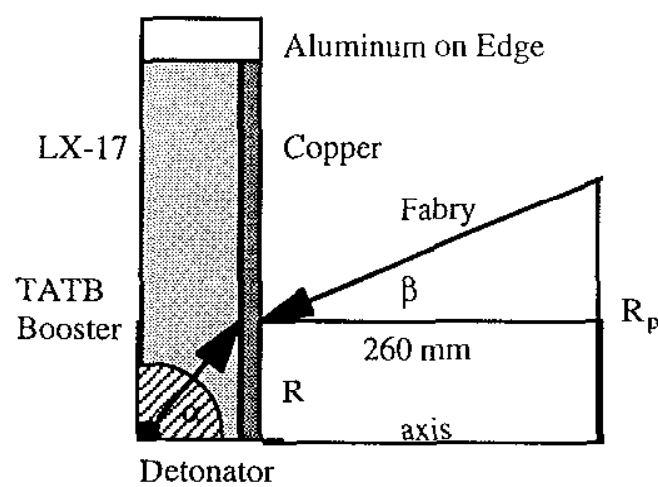

Figure 2. Schematic of the Bigplate geometry. $\alpha$ is the shock wave angle of incidence; $\beta$ is the Fabry angle. $R$ is the initial radial position to the Fabry beam on the copper.

Five Fabry interferometer beams are centered on the plate surface to measure the freesurface velocity. The beam diameters were about $1 \mathrm{~mm}$. The usual initial radial positions, $\mathrm{R}$, are 0 (on the axis), 10, 20,40 and $80 \mathrm{~mm}$. The initial nominal Fabry angles, $\beta$, are $0,4.5,7.5$, 10 and 11.5 degrees. These angles are selected to be about half-way between the initial and final 
plate positions. The radial distance defines the geometric angle of incidence, $\alpha$, which varies from $0^{\circ}$ on the axis to $76^{\circ}$ at $80 \mathrm{~mm}$. The Fabry probes are set $260 \mathrm{~mm}$ from the front surface. Each probe was checked for the position of its light spot on the metal surface.

Starting with 891D5, each of the five Fabry positions has two lengths. The fast Fabry starts before jump-off and runs about $2-3 \mu$ s. The slow Fabry starts about 1-2 $\mu$ s before the end of the fast sweep and may run for $10 \mu$ s or more. Once the long Fabry is past ist startup, it may be overlaid, without altering the times, with the short Fabry.

The point detonator creates a spherical wave that hits the copper plate on the axis first, then each point later farther out on the radius, as shown for the sequential Fabry curves in Figure 3. Also, the jump-off velocities decrease as we move outward from the axis.

The test was modeled in VHEMP with 10 $\mathrm{x} 800$ zones for the metal and $80 \times 400$ zones for the explosive. Uniform sizes of explosive zones were used to avoid refraction of the shock wave when it passes a mesh boundary at an oblique angle. A slide line was placed between the explosive and the metal. The JWL's used for the explosive EOS are listed in Table 1 at the end of the chapter.

\section{Defining Explosive Kinetics}

Most explosive Equations of State (EOS) are equilibrium, ie. they assume that the explosive puts out all its energy instantaneously. The most common is the analytical function, the JWL:

$$
\begin{aligned}
& P= A \exp \left(-R_{1} v\right)+B \exp \left(-R_{2} v\right)+ \\
& C / v^{l+\omega}
\end{aligned}
$$

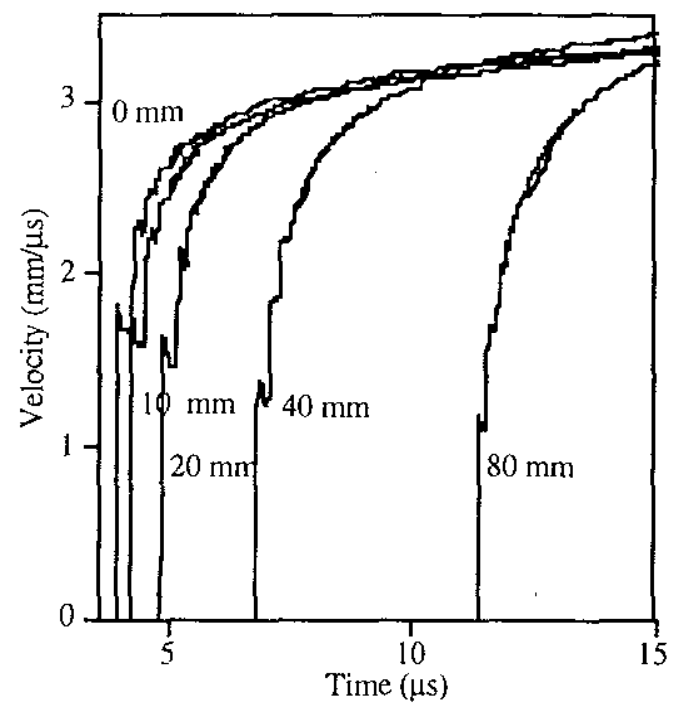

Figure 3. The five Fabry velocity curves for LX$04 / \mathrm{Cu}$ as plotted in real time. The highest one at $15 \mu \mathrm{s}$ is the $40 \mathrm{~mm}$ curve.

where $\mathrm{P}$ is the adiabat pressure, $\mathrm{v}$ the relative volume and all the rest are constants.

Equilibrium EOS's may be generated from thermochemical codes and transmitted using 1-D or 2-D cache tables. The P-v plane is shown in Figure 4 with an explosive adiabat in it. For many purists, the term EOS only refers to the P$v$ plane.

Most explosives take some time to react and put out their energy, so that time, as seen in Figure 3, becomes the third dimension, and the kinetic description that really describes the explosive traces a curve down through $\mathrm{P}-\mathrm{v}-\mathrm{t}$ 
space. The time-dependent code package used at LLNL is Lee-Tarver Reactive Flow, but this has been employed for lower pressure initiation problems and has not been used in production code runs.

The explosives of special interest at LLNL are, in order of nearly-ideal to non-ideal: LX-14, LX-04, ultrafine TATB, and LX-17. Three of these have been done in this Bigplate series. As an aid to considering ideality, a set of $12.7 \mathrm{~mm}$ radius copper-walled cylinders are shown in Fig. 5 . The curvatures increase from bottom to top in the ideality order set forth above. The curvature

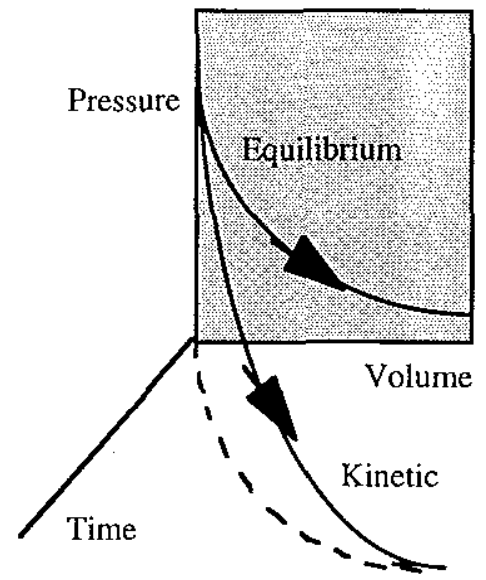

Figure 4. The explosive phase space of equilibrium $(\mathrm{P}-\mathrm{v})$ and kinetic EOS's $(\mathrm{P}-\mathrm{v}-\mathrm{t})$.

is the result of kinetics, ie. an explosive burn that takes time to occur. The longer the explosive takes to detonate, the more the side walls blow out and the more energy is sent sideways as reinforcement, thereby creating the curvature.

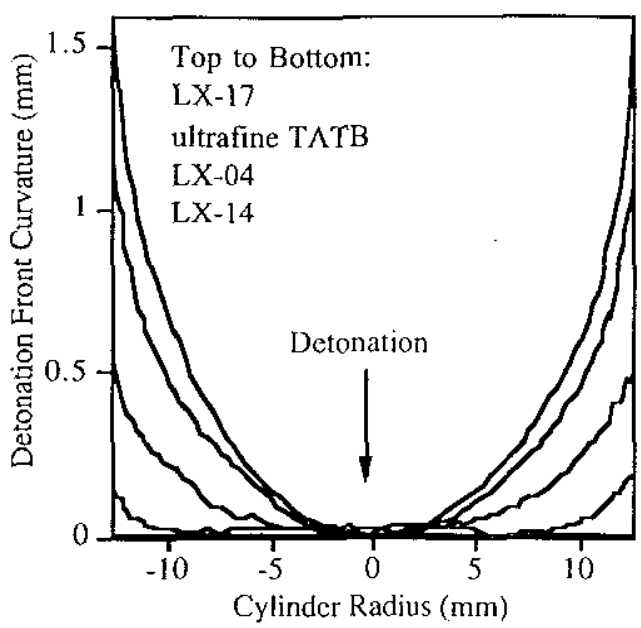

Figure 5. Detonation front curvature for 1 -inch diameter cylinders. The explosives become increasingly more ideal from top to bottom.

In summary, as the explosive becomes more non-ideal, we may expect the following problems in using an equilibrium EOS:

1) The velocity jump-off will be low, because the "spike" is missing. This is the extra compression that occurs to the explosive because only a little of it has reacted, and the product gases cannot fully push back.

2) A bad fit occurs at later time unless the EOS was specially fitted for an explosive part of that size. A size-dependent EOS is another giveaway that kinetics is present. 


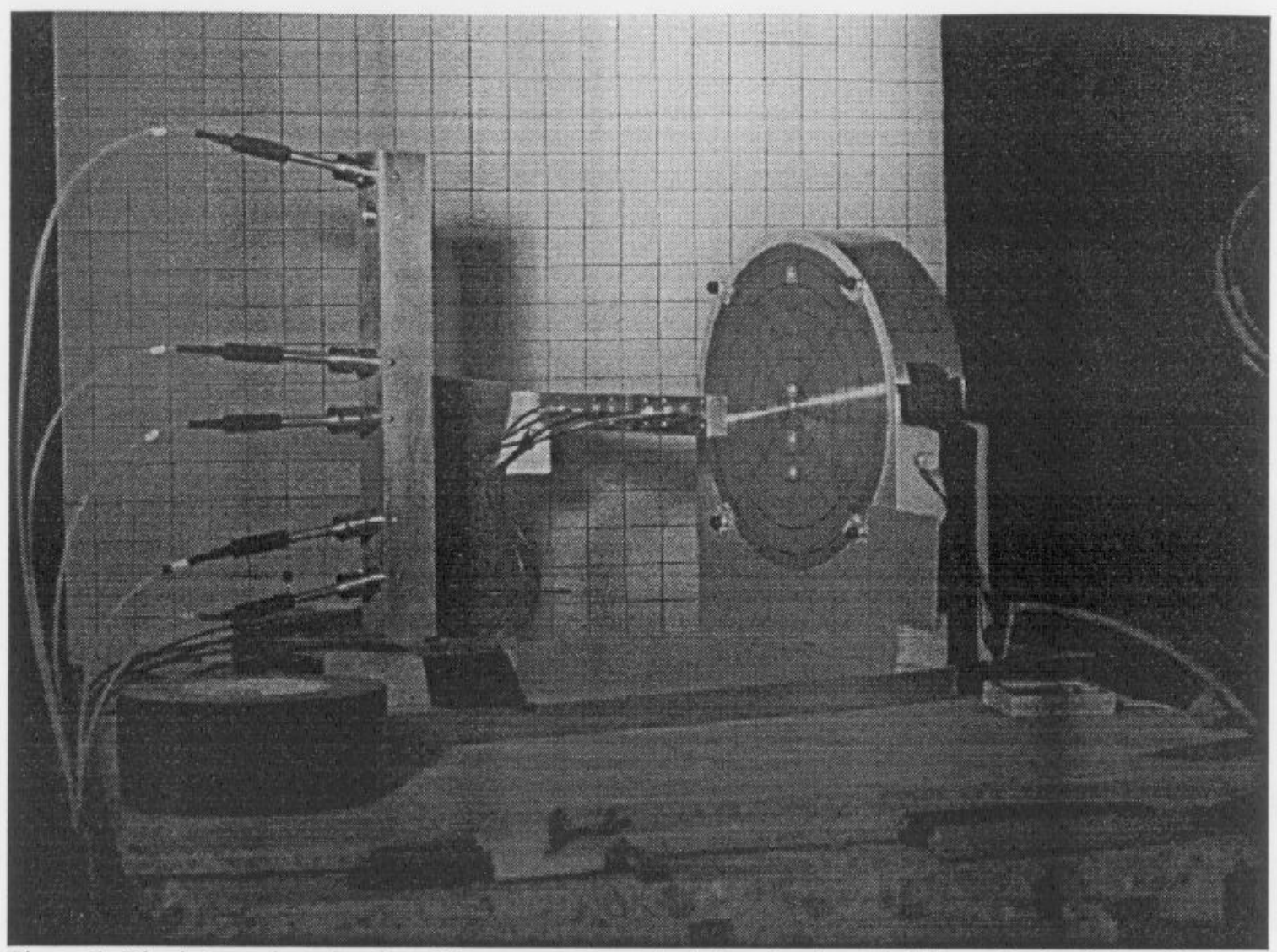

Figure 1. Bigplate ready to be shot. The copper plate sits in its aluminum holder at the far right with the green fabry beam dots visible. The horizontal bar in the middle holds pins; the Fabry probes are set into the vertical bar at the left. The shot is LX-17 2021B3.

Table 1. JWL's used in this work. The first three are traditional large-part JWL's for general use. The "ideal" LX-17 JWL works for the cylinder but not Bigplate. The TATB JWL is from the Cylinder Test.

\begin{tabular}{c|ccccc}
\hline & $\begin{array}{c}\text { LX-14 } \\
\text { 381 JWL }\end{array}$ & $\begin{array}{c}\text { LX-04 } \\
\text { traditional }\end{array}$ & $\begin{array}{c}\text { LX-17 } \\
\text { GLO97 }\end{array}$ & $\begin{array}{c}\text { LX-17 } \\
\text { "Ideal" } \\
\text { Cylinder }\end{array}$ & $\begin{array}{c}\text { Booster: } \\
\text { ultrafine } \\
\text { TATB }\end{array}$ \\
\hline$\rho_{\mathrm{o}}(\mathrm{g} / \mathrm{cc})$ & 1.835 & 1.865 & 1.905 & 1.909 & 1.80 \\
$\mathrm{~A}(\mathrm{Mb})$ & 7.55980 & 6.118 & 4.618235 & 6.86008 & 5.98713 \\
$\mathrm{~B}(\mathrm{Mb})$ & 0.22670 & 0.076670 & 0.120400 & 0.08032 & 0.0851513 \\
$\mathrm{C}(\mathrm{Mb})$ & 0.009824 & 0.006864 & 0.011881 & 0.01237 & 0.01321 \\
$\mathrm{R}_{1}$ & 4.44 & 4.07 & 4.04227 & 4.50 & 4.50 \\
$\mathrm{R}_{2}$ & 1.50 & 1.00 & 1.69856 & 1.50 & 1.50 \\
$\omega$ & 0.30 & 0.25 & 0.48019 & 0.26 & 0.29 \\
$\mathrm{E}_{\mathrm{o}}(\mathrm{Mb} * \mathrm{cc})$ & 0.1010 & 0.095 & 0.06918 & 0.086 & 0.082 \\
$\Gamma_{\mathrm{cj}}+1$ & 3.75500 & 3.690 & 3.64084 & 4.0370 & 3.9624 \\
$\mathrm{D}(\mathrm{cm} / \mu \mathrm{s})$ & 0.8830 & 0.8470 & 0.75763 & 0.7640 & 0.7478 \\
$\mathrm{P}_{\mathrm{cj}}(\mathrm{Mb})$ & 0.38102 & 0.36229 & 0.30034 & 0.27602 & 0.25403 \\
$\mathrm{v}_{\mathrm{cj}}$ & 0.73369 & 0.72900 & 0.72534 & 0.75229 & 0.74763
\end{tabular}




\section{Chapter 2. Sensitivity Analysis}

We here consider the various errors in the Bigplate test.

\section{Small Error: Explosive Density}

Table 1 (at the end of the chapter) lists the explosive densities. The LLNL densities were obtained by dimension/mass measurements. (The Bigplate HE was measured in Mechanical Engineering; the cylinders were measured by $L$. Daniels at HEAF) also taken were liquid displacement densities done at both LLNL and Pantex. The explosive in 891D5 was deliberately pressed lower than the usual $1.825-1.835 \mathrm{~g} / \mathrm{cc}$ LX-14 value.

A problem arises in comparing densities measured by different people and by different means. This is compounded in the case of LX-04 because this explosive is defined as a moulding powder, not as a pressed solid with a given density range. As an example, one of our older LX-04 parts has had reported densities of 1.865 $\mathrm{g} / \mathrm{cc}$ from Pantex in 1975, and 1.854 and 1.862 $\mathrm{g} / \mathrm{cc}$ as measured by different groups at LLNL in 1997. All of the LX-04 data is shown in Figure 1 , where cylinder detonation velocity vs. density is plotted. Most of the points and the line comes from 1960's size/mass measurements done at LLNL. The new cylinder data is shown in bold face. A density of $1.854 \mathrm{~g} / \mathrm{cc}$ seems possible in this context. It is also the opinion of Mechanical
Engineering that the size/mass values are better than the LLNL immersion values, and this appears to be true for the LX-17 results. Putting all this together, we estimate that the Bigplate explosive densities are good to $\pm 0.005 \mathrm{~g} / \mathrm{cc}$.

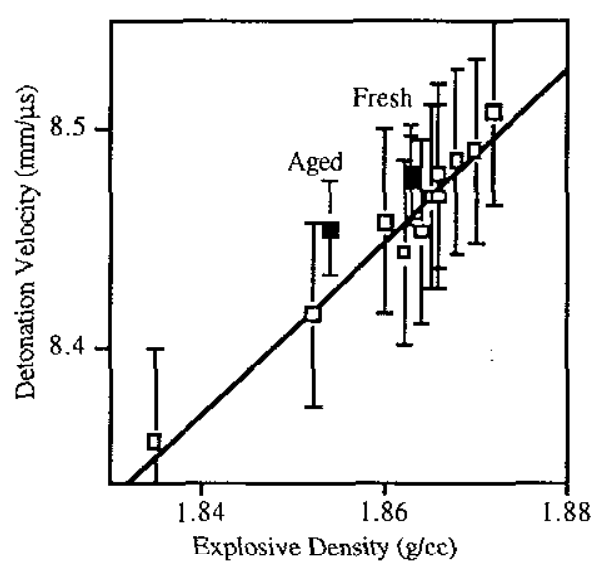

Figure 1. Detonation velocity vs. density for 25.4 and $50.8 \mathrm{~mm}$ diameter LX-04 cylinders with copper walls. The three new cylinders are shown in bold face. Most old shots date from the 1960's.

We next consider the effect of this density range. Figure 2 shows the code comparisons at 0 and $80 \mathrm{~mm}$ for LX-04 densities of $1.868,1.863$ and $1.858 \mathrm{~g} / \mathrm{cc}$, which produces a maximum copper velocity error of 0.007 to $0.01 \mathrm{~mm} / \mu \mathrm{s}-\mathrm{a}$ small value.

\section{Large Error: Plate Thickness}

In 1-D shots with thin metal plates, the plate thickness and material properties have historically been the limiting factor. This is also 
true here, especially with the improved FabryPerot interferometry being used to measure the front metal face velocity.

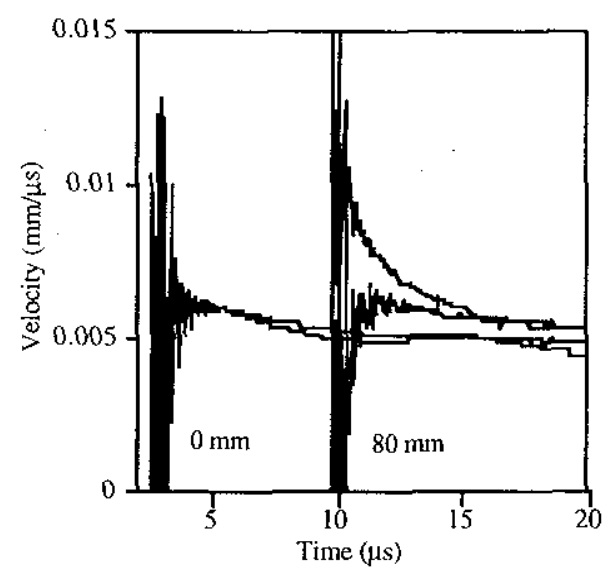

Figure 2. Code runs for LX-04 with $\pm 0.005 \mathrm{~g} / \mathrm{cc}$ density differences in the explosive. The differences in the copper velocities are shown.

The copper was oxygen free, and the manufacturing process was said to be:

1. Cut strip into small pieces. Press to a 70 mm thickness.

2. Anneal at $375^{\circ} \mathrm{C}$ for 15 minutes in a vacuum. Do a Rockwell hardness test.

3. Cold roll to $22 \mathrm{~mm}$ thickness. Bright dip and anneal.

4. Rough and final machine.

The copper plate thicknesses are supposed to be $0.50 \mathrm{~mm}$, but Table 1 shows a considerable variation. For a given plate, the listed tolerances are $\pm 0.05 \mathrm{~mm}$ and inspection procedures show that this range is met across each plate. The machine is supposed to capable of $\pm 0.008 \mathrm{~mm}$ but the inspection techniques were not set up to maintain or confirm this value, nor can the cutting equipment be expected to deliver this low value for plates set up and cut at different times.

In Table I we take the average thickness as obtained from the dimensions and the mass as being the number to use. The errors entering into it are the $\pm 0.3 \mathrm{~mm}$ tolerance in the radius and a $\pm 0.01 \mathrm{~g} / \mathrm{cc}$ copper density, which leads to a $\pm 0.005 \mathrm{~mm}$ estimated thickness error. The differerence between the average thickness and the micrometer-measured value ammounts to $\pm 0.009 \mathrm{~mm}$. The most recent shot $2021 \mathrm{~B} 1 \mathrm{had}$ Fabry probes at the $10 \mathrm{~mm}$ positions on both sides of the center point, and a difference of 0.04 $\mathrm{mm} / \mu$ s early-time velocity was seen. The code predicts that a thickness difference of $\pm 0.05 \mathrm{~mm}$ leads to a velocity difference of $\pm 0.12 \mathrm{~mm} / \mu \mathrm{s}$, which occurs about $2 \mu$ s after jump-off. Should the Fabry assymmetry really be caused by plate thickness variations, we have a $0.017 \mathrm{~mm}$ difference between the two $10 \mathrm{~mm}$ readings.

In summary, the average thickness appears well-known but the variability of thickness across the disk is less well known. The number lies between 0.01 and $0.05 \mathrm{~mm}$, and we shall take $0.518 \pm 0.025 \mathrm{~mm}$ as the mean copper thickness. Figure 3 shows the copper velocity difference in running the code with the error limits on the thickness. The jump-offs are supposed to be the same, and it takes $2 \mu$ s for the differences to appear. The thickness error by the analysis we have used wouid be \pm 0.06 $\mathrm{mm} / \mu \mathrm{s}$ or about $2 \%$ of a velocity of $3 \mathrm{~mm} / \mu \mathrm{s}$. 


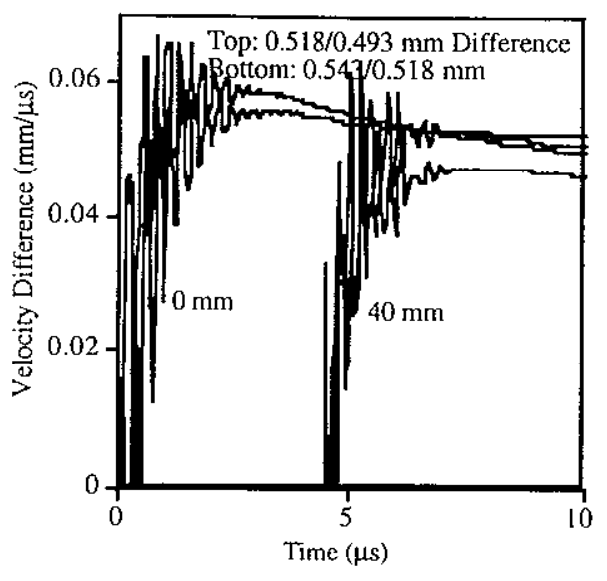

Figure. 3. Velocity difference for LX-04/copper in the code caused by variations of copper thickess of $0.518 \pm 0.025 \mathrm{~mm}$. This is currently the largest error in the Bigplate test.

\section{Small Error: Fabry Allignment}

Another error enters in the Fabry probe allignment. These are set $260 \mathrm{~mm}$ from the copper plate at an angle $\beta$ to the initial plate normal. These angles are uspposed to be $0^{\circ}$, $4.5^{\circ}, 7.5^{\circ}, 10.0^{\circ}$ and $11.5^{\circ}$. The probe radius from the axis is (Figure 2, Chapter 1)

$$
\mathrm{R}_{\mathrm{p}}=\mathrm{R}+260 \tan \beta
$$

The probes actually tilt somewhat in their holes drilled into the aluminum brackets that hold them. The probes are screwed into position and the laser spots where the copper would be are accurately measured. The probes are taken out again and reassembled just before the shot. Table 2 (at end of chapter) shows the measured radii for 2021B1, which was repeated three times because of shot delays. The distance $Y$ is the radius at right angles to $\mathrm{R}$ so that the initial Fabry angle becomes

$$
\beta=\tan ^{-1}\left\{\left[R_{p}-\left(Y^{2}+R^{2}\right)^{1 / 2}\right] / 260\right\}
$$

where dimensions are in $\mathrm{mm}$. The average Fabry angle in Table 2 is off of the nominal value by $0.18^{\circ}$ on the axis and by $0.02-0.04^{\circ}$ at the other positions. The standard deviation in the measured angle is $0.03-0.04^{\circ}$ for the three sets of measurements. As confirmed by the code runs, the angle error is too small to be of concern.

\section{Medium Error: Fabry Velocity}

A schematic of two Fabry fringes is shown in Fig. 4. Before firing, there are two lines that are straight with time, offset from the axis by the radii $r_{2}$ and $r_{1}$. These are actually

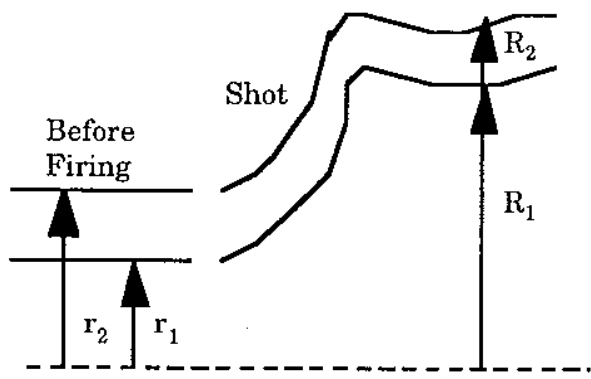

time $(\mu \mathrm{s})$

Figure 4. Schematic of the Fabry fringes with the radii indicated. Before and after jump-off are clearly segregated.

a function of time, although the changes will be small. After firing, the fringes readjust outward to radii $R_{2}$ and $R_{1}$. An arror function, $\Delta f$, has been created by Rex Avara that compares the various radii. This function, $\Delta f\left(r_{1}, r_{2}, R_{1}, R_{2}\right.$ for all fringes) is essentially a precision comparison.

Two typical error functions are shown for sample 2021 A5 in Figure 5. The initial value 
almost always decreases with time. The measured inital and average values with the standard deviations are listed in Table 3.

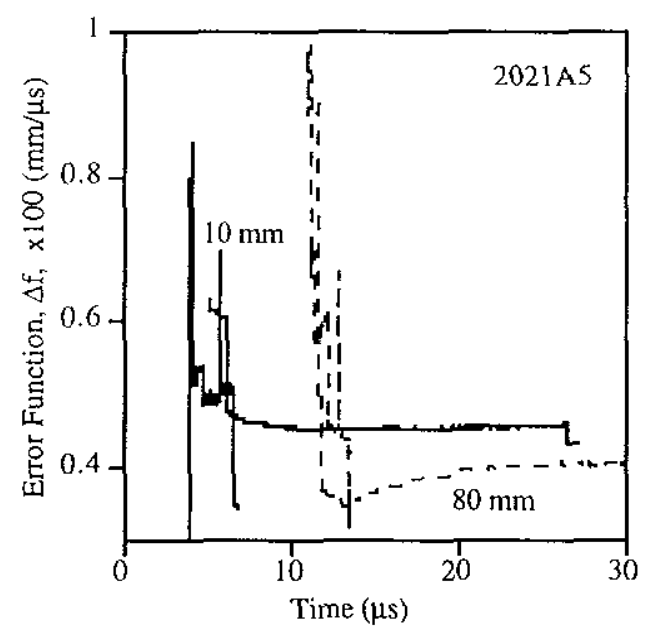

Figure 5. Typical error functions, showing the decrease after early time.

Table 3. Measured Fabry Error Functions.

\begin{tabular}{cccc}
\hline & \multicolumn{3}{c}{ Fabry error, $\Delta \mathrm{f}(\mathrm{mm} / \mu \mathrm{s})$} \\
\cline { 2 - 4 } & initial & average & stdev \\
\hline LX-14 & 0.011 & 0.007 & 0.002 \\
LX-04 & 0.010 & 0.006 & 0.002 \\
LX-17 & 0.013 & 0.007 & 0.002
\end{tabular}

The error in accuracy will be larger than the error function and must be estimated by considering all the factors such as optical distortion. Rex Avara estimates the worse-case error in accuracy to be $\pm 0.03 \mathrm{~mm} / \mu$ s for a single curve and $\pm 0.06 \mathrm{~mm} / \mu \mathrm{s}$ between two shots. The actual error might be less, and we relate it to the measured $\Delta$ function by

$$
\begin{aligned}
& \text { initial single curve } \approx 2 \Delta f \\
& \text { average single curve } \approx 3.5 \Delta f .
\end{aligned}
$$

For a single curve, the $\%$ accuracy for the velocity is $\pm 0.03 \mathrm{~mm} / \mu$ s or about $1 \%$. Ted Strand of this laboratory has done similar Fabry work and obtains about the same average value.

\section{Another consideration is the difference} between the short and long Fabrys, which lie over each other for 1-2 $\mu$ s (only the short Fabry does the jump-off). The differences are shown in Figure 6 and they are $\pm 0.05 \mathrm{~mm} . \mu \mathrm{s}$. The differences are larger at the start of the long Fabry, and these short sections may be thrown away.

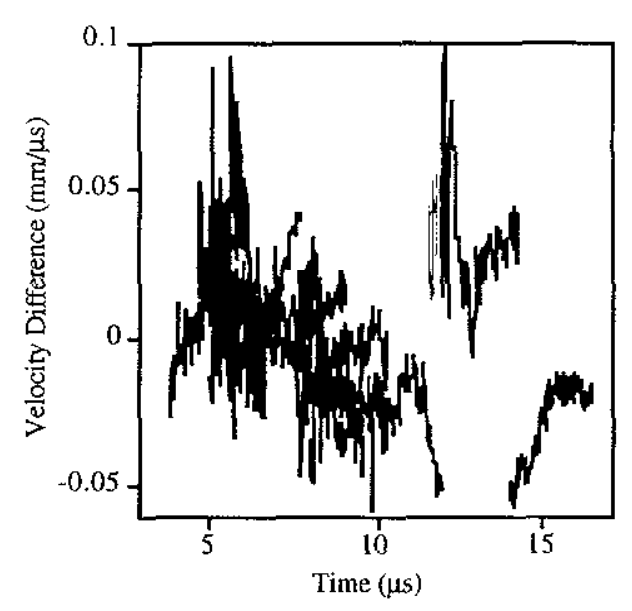

Figure 6. Short minus long Fabry velocities for the overlap portions of all Bigplate shots. The difference is $\pm 0.05 \mathrm{~mm} / \mu \mathrm{s}$. As-measured times are shown.

\section{Large Error: Fabry Timing}

The worst-case global fast Fabry timing errors in accuracy are estimated by Rex Avara to be: $\pm 0.03 \mu \mathrm{s}$ in a given run and $\pm 0.06 \mu \mathrm{s}$ between different runs. The slow Fabry errors are \pm 0.06 and $\pm 0.12 \mu \mathrm{s}$. For one curve, the error 
includes $1 / 3$ for the digitizers and $1 / 3$ for the det shaper. The error is considered to be to two standard deviations.

Once again,we may try to move closer to the individual shots by considering the rise times at jump-off, ie. the time from the final base-line value to the first peak velocity as measured by the fast Fabrys. Out of 38 measured jump-offs, 14 covered this distance between two adjacent measured points in time; the other 24 covered more than 2 points.

The measured rise time may be compared with the time for the detonation front to cross the spot of the laser beam, which is about $1 \mathrm{~mm}$ across and is thought to have a top-hat appearance as it comes from the light fiber. Let $\mathrm{X}$ be the thickness of the explosive to the front of the explosive, $R$ the radial distance and $U_{s}$ the detonation velocity. The average phase velocity sideways across the plate, $\langle\mathrm{W}\rangle$, between two radial positions, $R_{1}$ and $R_{2}$, is

$$
<W>=\frac{\left(R_{2}-R_{1}\right) U_{s}}{\left(R_{2}^{2}+X^{2}\right)^{1 / 2}-\left(R_{1}^{2}+X^{2}\right)^{1 / 2}}
$$

This analysis does not account for the shock wave crossing the copper plate.

The resulting measured rise times from the baseline to the maximum jump-off velocity are shown in Table 4, and they increase with increasing radius. There is a variation of calcuated times depending on the explosive and its thickness. However, all the measured rise times are less than calculated using Eq. 5. The reason is evident in Fig. 4: there are two different signals for the stationary and moving parts of the plate and only the moving part is considered in Table 4. This is large enough for a good reading when about $1 / 3$ of the laser spot has metal in motion underneath it.

Table 4. Calculated and measured Fabry rise times to the peak velocity (in $\mu$ s).

\begin{tabular}{c|cc|cc}
\hline $\begin{array}{c}\text { Radial } \\
\text { Position } \\
\text { (mm) }\end{array}$ & \multicolumn{2}{|c|}{$\begin{array}{c}\text { Calculated time } \\
\text { to cross }\end{array}$} & Spot & \multicolumn{2}{|l}{ Measured Rise } \\
\cline { 2 - 5 } & fastest & slowest & average & stdev \\
\hline 0 & 0 & 0 & 0.012 & 0.005 \\
10 & 0.032 & 0.053 & 0.011 & 0.006 \\
20 & 0.059 & 0.084 & 0.017 & 0.016 \\
40 & 0.093 & 0.106 & 0.028 & 0.022 \\
80 & 0.118 & 0.115 & 0.028 & 0.011
\end{tabular}

Another important time is the interval from baseline to the first large increase in velocity, even if it didn't make it to the maximum. This is the response time of the measuring system.

Rex Avara estimates that four times this is the approximate Fabry error in the length of the first velocity plateau:

$$
\begin{aligned}
& \pm \text { Error, first } \approx 2 *(\text { smallest jump-off } \\
& \text { plateau } \\
& \text { interval })
\end{aligned}
$$

These results are given in Table 5 .

\begin{tabular}{|c|c|c|c|}
\hline \multirow[b]{2}{*}{$\begin{array}{c}\text { Radial } \\
\text { Position } \\
\text { (mm) }\end{array}$} & \multicolumn{3}{|c|}{ Average Time $\Delta t(\mu s)$} \\
\hline & $\begin{array}{l}\text { First } \\
\text { Jump }\end{array}$ & $\begin{array}{c}\text { First } \\
\text { Plateau } \\
\text { Error }\end{array}$ & $\begin{array}{l}\text { stdev } \\
\text { First } \\
\text { Jump }\end{array}$ \\
\hline 0 & 0.011 & \pm 0.022 & 0.005 \\
\hline 10 & 0.008 & \pm 0.017 & 0.007 \\
\hline 20 & 0.014 & +0.029 & 0.015 \\
\hline 40 & 0.020 & \pm 0.040 & 0.021 \\
\hline 80 & 0.020 & \pm 0.040 & 0.007 \\
\hline
\end{tabular}

Table 5. Time interval for the greatest rise from baseline to almost full jump-off. 


\section{Large Error: Jump-Off Time at $80 \mathrm{~mm}$}

The detailed data is given in Chapter 3 but we mention here the jump-off time of the $80 \mathrm{~mm}$ Fabry signal relative to the jump-off at $0 \mathrm{~mm}$. This is shown in Table 6 along with the $\Delta t$ measured from the baseline to the jump-off velocity. The time delay needs to be much longer than $\Delta t$ in order to know that it is real. We also recall the $\pm 0.06 \mu$ s worst-case accuracy for the absolute time measurement between two Fabry curves.

Table 6. Time delay in the jump-off at the 80 $\mathrm{mm}$ radial position. The jump-off $\Delta \mathrm{t}$ is the measured time between the baseline and the first high velocity point, and it should be much less than the delay in order to demonstrate the effect.

\begin{tabular}{llccc}
\hline & & & & Time \\
& & \multicolumn{2}{c}{$\begin{array}{c}\text { Jump-Off } \Delta t(\mu \mathrm{s}) \\
\text { delay }\end{array}$} \\
\cline { 3 - 4 } & $0 \mathrm{~mm}$ & $80 \mathrm{~mm}$ & $80 \mathrm{~mm}$ \\
\hline 891D4 & LX-14 & 0.008 & 0.005 & 0.04 \\
891D5 & LX-14 & 0.015 & 0.022 & 0.11 \\
2021A1 & LX-04 & 0.014 & 0.008 & 0.01 \\
2021A2 & LX-04 & 0.016 & 0.028 & 0.14 \\
2021A3 & LX-04 & 0.005 & 0.032 & 0.12 \\
2021A4 & LX-04 & 0.010 & 0.019 & 0.13 \\
2021A5 & LX-04 & 0.010 & 0.010 & 0.14 \\
2021B2 & LX-17 & 0.016 & 0.020 & 0.14 \\
2021B3 & LX-17 & 0.004 & 0.018 & 0.10
\end{tabular}

In 7 out of 9 shots, the time delay at $80 \mathrm{~mm}$ is $0.10 \mu \mathrm{s}$ or greater. As shown in Chapter 3, this is not the case for the 10,20 or $40 \mathrm{~mm}$ positions. The effect is also seen in the single tantalum shot 2021A3. The cause of this effec $t$ is unknown. Two ideas are: 1) a "drag" on the detonation velocity caused by tangential motion along the inner plate boundary, as suggested by Jim Belak of LLNL, or 2) the opening of a 0.1 mm gap between the explosive and the metal. There is no known reason why a gap should appear at $80 \mathrm{~mm}$. This timing error may be "fixed" as far as EOS work is concerned by comparing the code and measured curves alone at $80 \mathrm{~mm}$.

\section{Large Error: Spall Timing}

Another timing problem occurs because of metal spall (see Chapter 3 for more detail). This is internal cracking of the plate parallel to the front face which occurs because of tension during the first velocity plateau. The front face of the plate becomes disconnected from the back and proceeds at constant velocity. Finally, the back part catches the front and pushes it higher in velocity. The extent of the problem is illustrated for $\mathrm{LX}-14 / \mathrm{Cu}$ in Figure 7, which plots the first

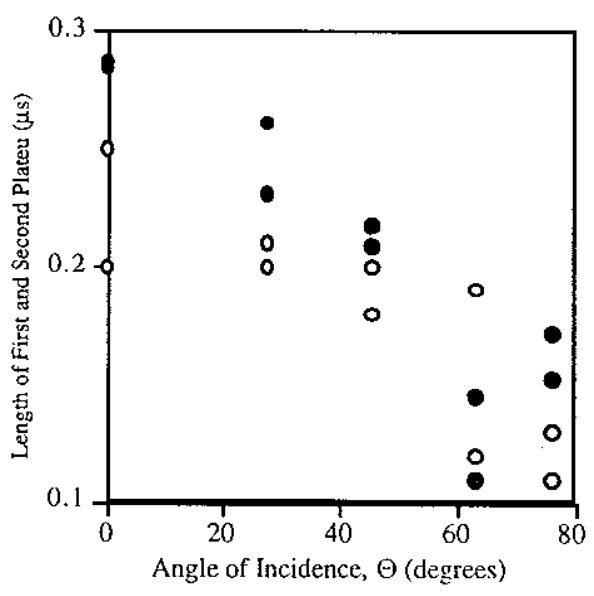

Figure. 7. The presence of metal spall as seen in the length of the first $(O)$ and second $(O)$ vleocity plateaux in $\mu$ s as a function of the angle of incidence of the shock wave in $\mathrm{LX}-14 / \mathrm{Cu}$. The probe radii are at $0,10,20,40$ and $80 \mathrm{~mm}$ from left to right. Maximum spall occurs on-axis. 
plateau length in $\mu$ s as a function of the explosive angle of incidence. We see that the plateau time is longer on-axis than at $80 \mathrm{~mm}$ radius. The lines are drawn assuming no spall at a $90^{\circ}$ angle. The spall is worst for $L X-14$, less for LX-04 and least for LX-17; this is the same order as the detonation pressures. The spall continues on the second plateau, where a "rebound" peak occurs, which also lengthens the plateau.

The extra times added beyond no spall are about $0.10-0.15 \mu$ s for the first plateau and about $0.10 \mu$ s for the second. As shown in Chapter 3, the spall may be modeled to some extent using the Steinberg-Guinan $p m i n$ model and varying the zoning. The first plateau time may be "fixed" for EOS comparison purposes by considering the data and the code output at each radius linked halfway between the first and second jumps. The second plateau time cannot be dealt with by this method.

From Figure 8, we see that the scatter is considerable so that spall is a random and uncontrollable factor that does appear even in thin metal plates. The randomness is less than the time accuracy error but is undoubtedly real.

\section{Summary}

Table 7 at the end of the chapter summarizes all of the errors discussed above. All the velocity errors may be combined to produce a value of $\pm 0.066 \mathrm{~mm} / \mu \mathrm{s}$. 
Table 1. Dimensions, masses and densities of the Bigplate parts.

\begin{tabular}{|c|c|c|c|c|c|c|c|c|c|c|c|}
\hline \multirow[b]{3}{*}{$\begin{array}{c}\text { Shot } \\
\text { Series }\end{array}$} & \multirow[b]{3}{*}{$\begin{array}{c}\text { Firing } \\
\text { Date }\end{array}$} & \multirow[b]{3}{*}{ Expl. } & \multicolumn{5}{|c|}{ HE Density $(\mathrm{g} / \mathrm{cc})$} & \multicolumn{2}{|c|}{ Metal only } & \multicolumn{2}{|c|}{ Metal + estane } \\
\hline & & & \multirow{2}{*}{$\begin{array}{c}\text { "dry" } \\
\text { mass/ } \\
\text { dimen. }\end{array}$} & \multirow{2}{*}{$\begin{array}{l}\text { "wet" } \\
\text { immer- } \\
\text { sion }\end{array}$} & \multirow{2}{*}{\multicolumn{2}{|c|}{$\begin{array}{c}\text { Metal } \\
\text { Radius } \\
(\mathrm{mm})\end{array}$}} & \multirow[b]{2}{*}{$\begin{array}{c}\text { Mass } \\
(\mathrm{g})\end{array}$} & \multicolumn{2}{|c|}{ Thickness (mm) } & \multirow[b]{2}{*}{$\begin{array}{l}\text { Micro- } \\
\text { meter }\end{array}$} & \multirow[b]{2}{*}{$\begin{array}{c}\text { Mass } \\
(\mathrm{g})\end{array}$} \\
\hline & & & & & & & & $\begin{array}{l}\text { Micro- } \\
\text { meter }\end{array}$ & $\begin{array}{l}\text { from } \\
\text { Mass }\end{array}$ & & \\
\hline 891D4 & Dec-95 & $\mathrm{LX}-14$ & 1.831 & 1.827 & $\mathrm{Cu}$ & 99.50 & 146.28 & 0.540 & 0.526 & & \\
\hline 891D5 & Dec-95 & LX-14 & 1.807 & 1.804 & $\mathrm{Cu}$ & 97.85 & 134.85 & 0.504 & 0.501 & & 135.2 \\
\hline 2021A1 & Aug-96 & LX-04 & 1.868 & 1.868 & $\mathrm{Cu}$ & 99.44 & NA & 0.533 & 0.529 & 0.552 & I48.4 \\
\hline 2021A2 & Oct-96 & LX-04 & 1.870 & 1.867 & $\mathrm{Cu}$ & 99.50 & 145.90 & 0.529 & 0.525 & 0.540 & 147.3 \\
\hline $2021 \mathrm{~A} 4$ & Feb-97 & LX-04 & 1.862 & 1.866 & $\mathrm{Cu}$ & 99.49 & 146.50 & 0.528 & 0.527 & & \\
\hline 2021A5 & Aug-97 & LX-04 & 1.861 & & $\mathrm{Cu}$ & 99.48 & 140.40 & 0.500 & 0.505 & & \\
\hline $2021 B 1$ & Feb-98 & $\mathrm{LX}-17$ & 1.906 & 1.875 & $\mathrm{Cu}$ & 99.51 & 143.90 & 0.530 & 0.517 & & \\
\hline 2021B2 & Sep-97 & LX-17 & 1.906 & 1.896 & $\mathrm{Cu}$ & 99.51 & 142.50 & 0.510 & 0.512 & & \\
\hline $2021 B 3$ & Dec-97 & LX-17 & 1.907 & 1.898 & $\mathrm{Cu}$ & 99.52 & 143.78 & 0.500 & 0.517 & & \\
\hline 2021A3 & Feb-97 & LX-04 & 1.868 & 1.870 & $\mathrm{Ta}$ & 99.47 & 267.90 & 0.505 & 0.516 & & \\
\hline
\end{tabular}

* 202IAl use estane mass less $1.4 \mathrm{~g}$.

Table 2. Measured Fabry beam distances for 2021B1, done three times over 6 months. Positive and negative radii are on opposite sides of the center. \#4 is taken from the pre-shot framing camera picture and is thought to less accurate due to distortion.

\begin{tabular}{ccccc|ccc}
\hline \multicolumn{5}{c|}{ Radial Distance, R (mm) } & \multicolumn{3}{|c}{ Sideways (mm) } \\
\hline nom & $\# 1$ & $\# 2$ & $\# 3$ & $\# 4$ & $\# 1$ & $\# 2$ & $\# 3$ \\
\hline 0 & 0.25 & -0.30 & -0.15 & 0.06 & 0.50 & 0.68 & 0.77 \\
0 & -0.08 & -0.31 & -0.50 & & 0.85 & 0.82 & 0.89 \\
10 & 10.26 & 9.89 & 9.86 & 10.01 & 0.89 & 0.72 & 0.80 \\
10 & 10.35 & 10.08 & 9.96 & & 0.77 & 0.70 & 0.92 \\
-20 & -20.08 & -20.19 & -19.88 & -20.32 & 0.54 & 0.42 & 0.77 \\
-20 & -20.19 & -20.30 & -20.49 & & 0.62 & 0.61 & 0.73 \\
-40 & -40.05 & -40.15 & -40.00 & -40.37 & 0.31 & 0.23 & 0.19 \\
-40 & -40.19 & -40.30 & -40.00 & & 0.47 & 0.49 & 0.58 \\
80 & 80.12 & 80.11 & 80.00 & 80.49 & 0.77 & 0.69 & 0.42 \\
80 & 80.27 & 80.42 & 80.07 & & 0.62 & 0.68 & 0.72
\end{tabular}


Table 7. Summary of Bigplate accuracies.

\begin{tabular}{llccc} 
& Cause of error & Error & $\begin{array}{c}\text { Velocity } \\
(\mathrm{mm} / \mu \mathrm{s})\end{array}$ & $\begin{array}{c}\text { Time } \\
(\mu \mathrm{s})\end{array}$ \\
\hline Copper & Plate Thickness & $0.025 \mathrm{~mm}$ & 0.06 & \\
Velocity & Explosive Density & $0.005 \mathrm{~g} / \mathrm{cc}$ & 0.01 & \\
& Fabry Probes & $0.2^{\circ}$ & 0 & \\
& Fabry accuracy & $0.025 \mathrm{~mm} / \mu \mathrm{s}$ & 0.025 & \\
& & & & \\
& Total Error & & $\mathbf{0 . 0 6 6}$ & \\
& \% Error at 3 mm/ $\mu \mathrm{s}$ & $1.2 \%$ & & \\
& T. Strand \% Error & 0.4 to $1.4 \%$ & & 0.03 \\
\hline Absolute & fast Fabry-one curve & & & 0.06 \\
Time- Fabry fast Fabry-two curves & & & 0.06 \\
& slow Fabry-one curve & & 0.12 \\
& slow Fabry-two curves & & 0.01 \\
& Fabry Jump-Off Smallest Interval & & $0.02-0.04$ \\
\hline Absolute & Fabry First Plateau Times & & 0.1 \\
Time- & Jump-Off Error 80 mm & & $0.1-0.15$ \\
Sample & 0 mm First Plateau Extra Spall Time & & 0.1
\end{tabular}




\section{Chapter 3. Data and Analysis}

\section{Basic Data}

A list of Bigplate data is given in Table 1 (at the end of the chapter). The nominal initail radial distances to the Fabry beams and the geometric angles of incidence, $\alpha$, from the detonator are given. Next comes the measured jump-off times, which are not in terms of time from the detonator but start earlier from the load ring. The time difference compares the jump-off time at the later radial positions with the jumpoff time on the axis. The expected time at the ith radius relative to the on-axis jump-off, $t_{\mathrm{ci}}$, is

$$
t_{e i}=\frac{\left(R^{2}+X^{2}\right)^{1 / 2}-R}{U_{s}}+t_{i}-t_{0}
$$

where $\mathrm{R}$ is the radial distance, $\mathrm{X}$ is the explosive thickness and $t$ is the time for the shock wave to cross the metal the first time, which is calculated below. A glance at Table 1 shows that there is an additional $0.1 \mu$ s lag between the axis jumpoff and the $80 \mathrm{~mm}$ jump-offs for 7 of the 9 shots. Two possible reasons were mentioned in Chapter 2.

Next in Table 1 we list the jump-off velocities, which decrease as we move from the axis to the edge. Next comes the data describing the first and second velocity plateaus. For the first plateau, we list the length and the extent of the velocity pullback as it experiences tension.
The second plateau length and the velocity increase of the "rebound" are given. The rebound presumably occurs as the two parts of the plate completely catch up and boost the velocity.

Four sets of 0 and $80 \mathrm{~mm}$ velocity curves are shown in Figure 1 at the end of the chapter. The curves are moved in time so that they overlap halfway between the first and second plateaus. There is spall in every case on or near the axis. The copper shows much less spall at 80 $\mathrm{mm}$ so that the comparison is dramatic. The spall causes an increase in both the first and second plateau times for copper. The tantalum looks better at first glance but all the plateaus are longer than expected, as can be seen by comparing tantalum and copper at $80 \mathrm{~mm}$.

Figure 2 (end of chapter) shows all five curves for the worst case: $891 \mathrm{D} 5, \mathrm{LX}-14 / \mathrm{Cu}$. The randomness of spall is seen especially in the abnormally lengthened second plateau at $40 \mathrm{~mm}$, where spall is not expected to be so bad.

Figure 3 shows slapper-driven 1-D curves for $0.51 \mathrm{~mm}$ thick copper and tantalum plates. The first plateaus do not show jump-off because the Fabry interferometry was not so good ten years ago. As shown by the lack of rebound on the second plateau, the spall in 1-D is much less than that in Bigplate. In 2-D Bigplate, the cracking starts on axis and has time to expand sideways with the detonation wave. The tantalum second plateaus in Figure 3 are only slightly longer than those for copper. 


\section{Code Modeling of Spall}

The material model for the copper was the Steinberg-Guinan model in which the pressure in copper is set to zero if it is less than pmin. Once the pressure recovers above pmin, the stress deviators are calculated again and the zones heal.

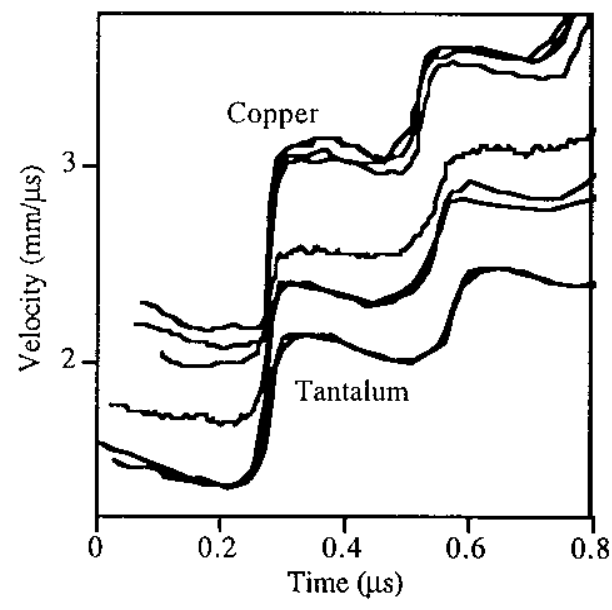

Figure 3. Slapper-driven 1-D plate shots with copper (LX-14) and tantalum (LX-14, LX-04 and $\mathrm{LX}-17$ ), all with $0.51 \mathrm{~mm}$ metal thicknesses. Jump-off was not measured in these old Fabrys.

Figure 4 (at the end of the chapter) shows the early history for LX-04/Cu shots at 0 and 80 $\mathrm{mm}$ for various zonings, which are listed in Table 2. The baseline of $4 \mathrm{~mm} / z$ zone (A) is considered high zoning for production. However, it does not spall enough, which led to the other schemes. The values of pmin and slideline friction were kept at $-0.012 \mathrm{Mb}$ and 0 in Figure 4. Making the copper mushier or increasing the friction did not help.

As seen in Figure 4, increasing the zoning with the pmin model lengthens the first plateau at $0 \mathrm{~mm}$ but makes it too flat and slightly high.

The model does put in the "rebound" on the

Table 2. variable zoning studies on $\mathrm{LX}-04 / \mathrm{Cu}$.

\begin{tabular}{rcccc}
\hline & Zones & Zones & \multicolumn{2}{c}{ Zones/mm } \\
\cline { 4 - 5 } & HE & copper & HE & copper \\
\hline E & $120 \times 600$ & $20 \times 1200$ & $6 \times 6$ & $40 \times 12$ \\
D & $80 \times 400$ & $20 \times 800$ & $4 \times 4$ & $40 \times 8$ \\
B & $100 \times 500$ & $15 \times 1000$ & $5 \times 5$ & $30 \times 10$ \\
J & $80 \times 400$ & $10 \times 2000$ & $4 \times 4$ & $20 \times 20$ \\
A & $80 \times 400$ & $10 \times 800$ & $4 \times 4$ & $20 \times 8$
\end{tabular}

second plateau so it is modeling the spall. The $\mathrm{E}$ zoning is probably the best with $A$ the worst and $\mathrm{B}$ a good compromise. However, at $80 \mathrm{~mm}$, all the zoning approaches are too high in value, although $E$ and $B$ have the right width, which is wider than A. This shows that spall does appear to occur at $80 \mathrm{~mm}$, although it is not dramatic enough to cause a "rebound" peak.

High resolution zoning is necessary to calculate the spall correctly, although the pmin model is too simple. Spall is a time-dependent coagulation of voids and is the metal equivalent of Reactive Flow. We do not seem to have ever reached zoning convergence and the spall model and the explosive EOS are intimately interconnected. The question of square versus rectangular zones is also left unanswered.

\section{Spall Summary}

The effect of metal spall in Bigplate is larger than error. It consists of 1) an on-axis first plateau delay that is $0.1 \mu \mathrm{s}$ long and decreases to zero at $80 \mathrm{~mm}$, and 2) an on-axis second plateau delay that is 0.05 to $0.1 \mu$ s long and decreases 
to zero at $80 \mathrm{~mm}$. A non-spall effect is the 0.1 $\mu$ s delay in jump-off at $80 \mathrm{~mm}$. The first and third effects may be negated by lining code and data curves halfway between the first and second plateaus to comparison. This will be done at each radial position, because the time delays make it impossible to accurately translate all five curves at once in time. The above fitting lowers the timing error between data and code curves to perhaps twice the $\pm 0.03 \mu$ s Fabry time measurement error.

It would be helpful to have a timer that gives us a reference point back somewhere in the explosive; if not the detonator, then a gauge somewhere in the main charge. This would . relieve us of using the axis jump-off time, which has one metal transit time folded into it.

As we shall see below, spall does not appear to affect our ability to confirm the validirty of an explosive EOS to the level of accuracy in this work. This is because the metal pieces "catch up" and the energetics over time appear relatively unaffected.

\section{The Jump-Off Discrepancy}

As mentioned in the prceeding chapter, a 0.1 $\mu$ s lag occurs at the $80 \mathrm{~mm}$ position between the code and the data for 7 of 9 shots. The data is always late.

We used the $5 \mathrm{zone} / \mathrm{mm}$ code to obtain the time for the shock wave to cross the copper for the first time. This was obtained from the time differences of linear pressure startup in the outer metal zone and the outermost explosive zone.
The results are shown for $\mathrm{LX}-04 / \mathrm{Cu}$ in Table 3. High resolution zoning, using scheme $B$, is needed to obtain this time accurately. The transit time is found to be essentially constant with the angle of incidence and this is used above to obtain the expected jump-off times. The measured angle of refraction of the shock wave is almost twice as large as might be expected from the Sine Law in optics. This is caused by the moving of the interface as the wave passes.

Table 3. Time for the shock wave to cross the copper the first time for LX-04/Cu.

\begin{tabular}{ccccc}
\hline Code & $\begin{array}{c}\text { Code } \\
\text { Transit }\end{array}$ & $\begin{array}{c}\text { Cu Wave } \\
\text { Time }\end{array}$ & $\begin{array}{c}\text { Angle } \\
\text { of Inci- }\end{array}$ & \multicolumn{2}{c}{$\begin{array}{c}\text { Angle of } \\
\text { Velocity }\end{array}$} & $\begin{array}{c}\text { dence } \\
(\mu \mathrm{s})\end{array}$ & \begin{tabular}{c} 
Refraction $(\mathrm{deg})$ \\
\cline { 4 - 5 }$(\mathrm{mm} / \mu \mathrm{s})$
\end{tabular} & (deg) & Code & Optics \\
\hline 0.105 & 4.8 & 0 & 0 & 0 \\
0.110 & 4.5 & 27 & 17 & 9 \\
0.106 & 4.7 & 45 & 25 & 14 \\
0.103 & 4.9 & 63 & 35 & 19 \\
0.101 & 5.0 & 76 & 34 & 19
\end{tabular}

Figure 5 shows a comparison of code and data for $\mathrm{LX}-04 / \mathrm{Cu}$. The $80 \mathrm{~mm}$ curves have been moved $7 \mu$ s forward in time for display purposes but they keep their relative temporal positions to each other. We see that the $B$ zoning model makes the spall look more realistic but both $\mathrm{B}$ and $\mathrm{A}$ have jump-offs beginning 0.1 $\mu$ s too soon. The data is listed in detail in Table 1.

Jim Belak suggests that the detonation wave is "dragged" down by its interaction with the metal plate as moves tangentially to the far 80 $\mathrm{mm}$ position. If this were the case, the code would not see it because of the program burn package. 


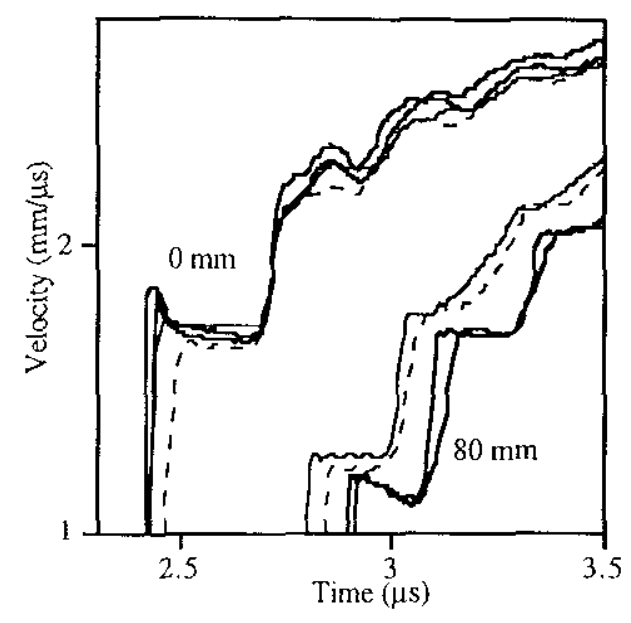

Figure 5. Comparison of code and data for $2021 \mathrm{~A} 2$ and A5 LX-04/Cu. The light full lines are the data; the heavy line is scheme $\mathrm{D}$ and the dashed line is $A$. The $80 \mathrm{~mm}$ curves have been moved up in time for comparison but remain locked relative to each other. The $0.1 \mu$ s lag at $80 \mathrm{~mm}$ is evident.

\section{Code Comparisons for the Explosive EOS}

Figure 6 (at the end of the chapter) shows the measured less code velocity differences for four Bigplate shots. At each radial position, the measured and calculated curves are set together in time at the halfway point of the first and second plateaus. The JWL's are the first three general purpose EOS's listed in Table 1, Chapter 1.

The agreeement is good for LX-14 and LX04 , ie. the velocity difference is within the error band described in Chapter 2. This is not true for $\mathrm{LX}-17$, which is known to have considerable kinetic effects. Some of the short time and all of the long time behavior is outside of error. The bad fit of LX-17 to a JWL appears in virtually every geometry from simple to complex and is a main indication of non-ideality.

\section{Comparison of Explosives}

Two sets of explosives may be compared directly in this work. Figure 7 shows the difference between the two LX-14 shots 891D4 and 891D5. Only the short Fabry was done on $891 \mathrm{D} 4$ so that $2.5 \mu \mathrm{s}$ is all we get. The densities of the two were 1.827 and $1.804 \mathrm{~g} / \mathrm{cc}$, so that 891D4 alone is true LX-I4. No diffence is seen, which gives us information as to the sensitivity of the density. Generally, a JWL is used for a band of densities about its listed one, and this practice here appears to be justified. The JWL used is for $1.835 \mathrm{~g} / \mathrm{cc} \mathrm{LX}-14$.

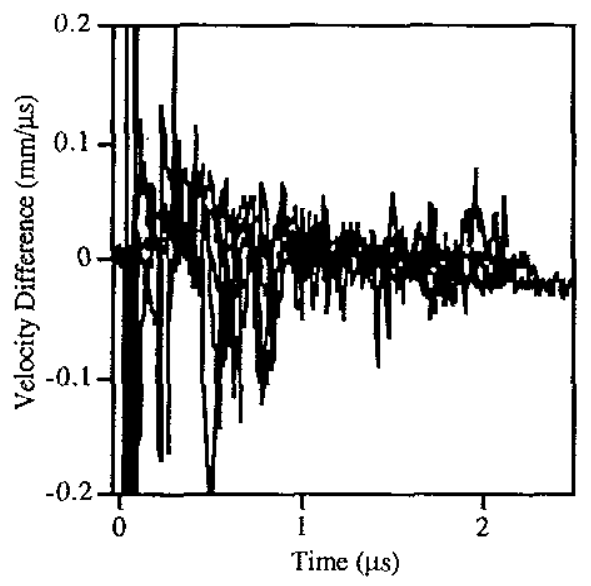

Figure 7. Velocity differences between LX-14 measurement and code in shots 891D4 and $891 \mathrm{D} 5$ for all five radial positions. No difference is seen in the first $2.5 \mu \mathrm{s}$, all that was taken for 891D4. The two densities were 1.827 and 1.804 $\mathrm{g} / \mathrm{cc}$. All times start at zero.

Figure 8 shows the comparison of the LX$04 / \mathrm{Cu}$ shots with all data being subtracted from 2021A2. All samples were made from the same batch. The baseline samples $2021 \mathrm{~A} 1$ and 2021A2 were stored as moulding powder for 22 years then pressed for these experiments. The 2021A4 and 2021A5 samples were pressed in 
1974 and stored elsewhere until returned for this work. All data lies within $\pm 0.05 \mathrm{~mm} / \mu$ s despite the slight dimensional differences listed in

Chapter 1.

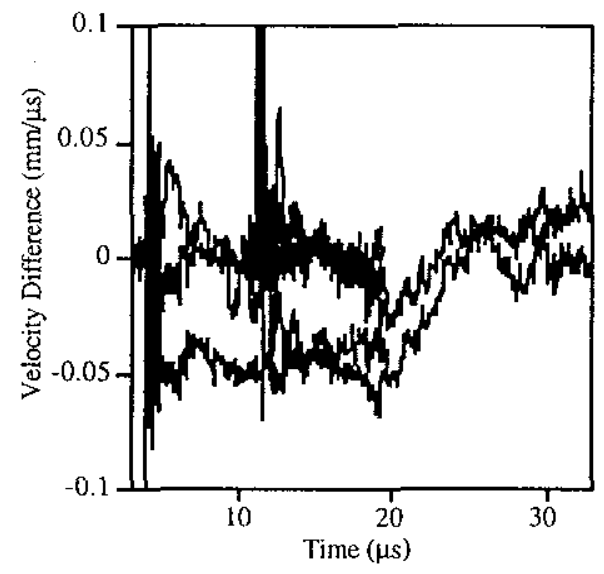

Figure 8. Velocity differences between the LX$04 / \mathrm{Cu}$ shots. All shots are compared to 2021A2. Times are reset to zero. No differences are seen between the baseline and aged samples.

\section{CHEETAH}

CHEETAH is an equilibrium thermochemical code developed by Larry Fried at LLNL and used extensively at other laboratories. $^{1-3}$ It assumes that an explosive decomposes instantly into products, eg. TATB turns into the products seen in Table 4.

A large thermodynamic library exists for the reactacts and products, including heats of formation, heat capacities and compressibilities. The code equilibrates each product via minimization of the free energy with the other products at every temperature and calculates the pressure, energy and composition as a function of volume. This code is like a JWL in that it has a $\mathrm{C}-\mathrm{J}$ point and detonation is instantaneous. It is unlike A JWL in that it has the capability to go off-adiabat if a reshock occurs.

Table 4. Products formed from the detonation of TATB

\begin{tabular}{ccc}
\hline $\begin{array}{c}\text { Main } \\
\text { Products }\end{array}$ & $\begin{array}{c}\text { Lesser } \\
\text { Products }\end{array}$ & \\
\hline $\mathrm{CO}_{2}$ & $\mathrm{NH}_{3}$ & $\mathrm{C}_{2} \mathrm{H}_{6}$ \\
$\mathrm{CO}$ & $\mathrm{CF}_{4}$ & $\mathrm{NO}_{2}$ \\
$\mathrm{~N}_{2}$ & $\mathrm{HCN}$ & \\
$\mathrm{H}_{2} \mathrm{O}$ & $\mathrm{HCOOH}$ & \\
$\mathrm{CH}_{4}$ & $\mathrm{NO}$ & \\
$\mathrm{HF}$ & $\mathrm{C}_{2} \mathrm{H}_{4}$ & \\
$\mathrm{H}_{2}$ & $\mathrm{CH}_{3} \mathrm{OH}$ & \\
$\mathrm{C}($ solid $)$ & $\mathrm{O}_{2}$ & \\
&
\end{tabular}

Equilibrium CHEETAH has been linked with the 2-D code HEMP by way of a 2-D cache table. The table remembers previous calculations in specific regions of $\mathrm{P}-\mathrm{v}$ space and uses the data from the table if possible rather than recalculating.

An experimental version of the code exists called KINETIC CHEETAH. This code adds the time-dependent burn by way of rate terms such as

$$
\frac{\mathrm{d}[\mathrm{TATB}]}{\mathrm{dt}}=\mathrm{AP}^{2}(1-[\text { ТАТB }])
$$

The rates are inferred from cylinder Size Effect and curvature experiments. This code has been linked with the 1-D code KOWIN and is being linked with HEMP. It is not known whether a cache table will work with time-dependence.

Figure 9 shows the results on non-ideal LX-17 using Equilibrium CHEETAH. It is close 
but the lowness at jump-off and later suggests the absence of the spike and kinetics.

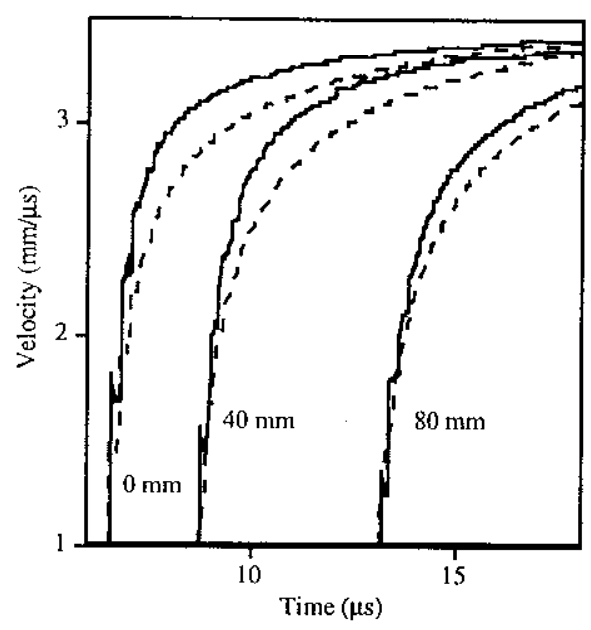

Figure 9. LX-17/Cu Bigplate data (solid lines) and Equilibrium CHEETAH (dashed lines) runs. The low code runs are good but their lowness indicates the absence of kinetics. CHEETAH is here linked with HEMP.

\section{KINETIC CHEETAH has not yet been} linked with HEMP, but it has with the 1-D code KOWIN. Figure 10 shows results for $20 \mathrm{~mm}$ LX-17 pushing a $0.51 \mathrm{~mm}$ tantalum plate. A slapper detonator is used with an LX-10 booster. Equilibrium CHEETAH is low as might be expected with the lack of kinetics. The addition of a time-dependent TATB reaction raises the velocity to the measured values.

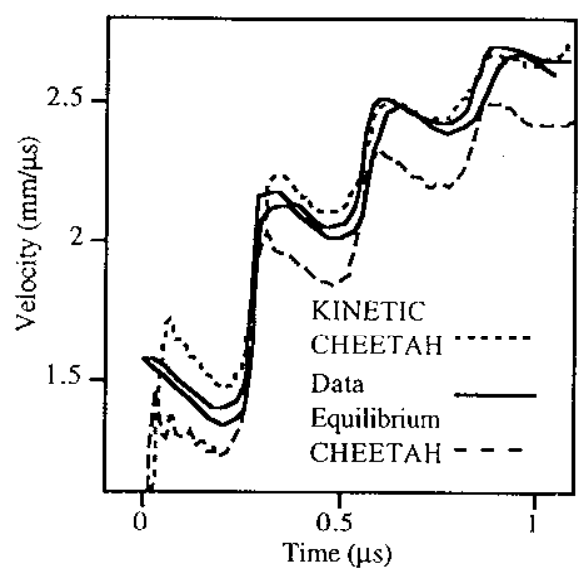

Figure 10. Improvement of the LX-17 velocity by going from Equilibrium to KINETIC CHEETAH on a l-D LX-17/Ta plate shot. CHEETAH is here linked with KOWIN.

\section{References}

1. L. E. Fried and P. C. Souers, CHEETAH: $A$ Next Generation Thermochemical Code, Lawrence Livermore National Laboratory report UCRL-ID-117240 (1994).

2. L. E. Fried, CHEETAH User's Manual, Lawrence Livermore National Laboratory, UCRL-MA-I17541 Rev. 3, 1996.

3. L. E. Fried and P. C. Souers, "BKWC: An Empirical BKW Parametrization based on Cylinder Test Data," Propellants, Explosives, Pyrotechnics 21, 215-223 (1996). 

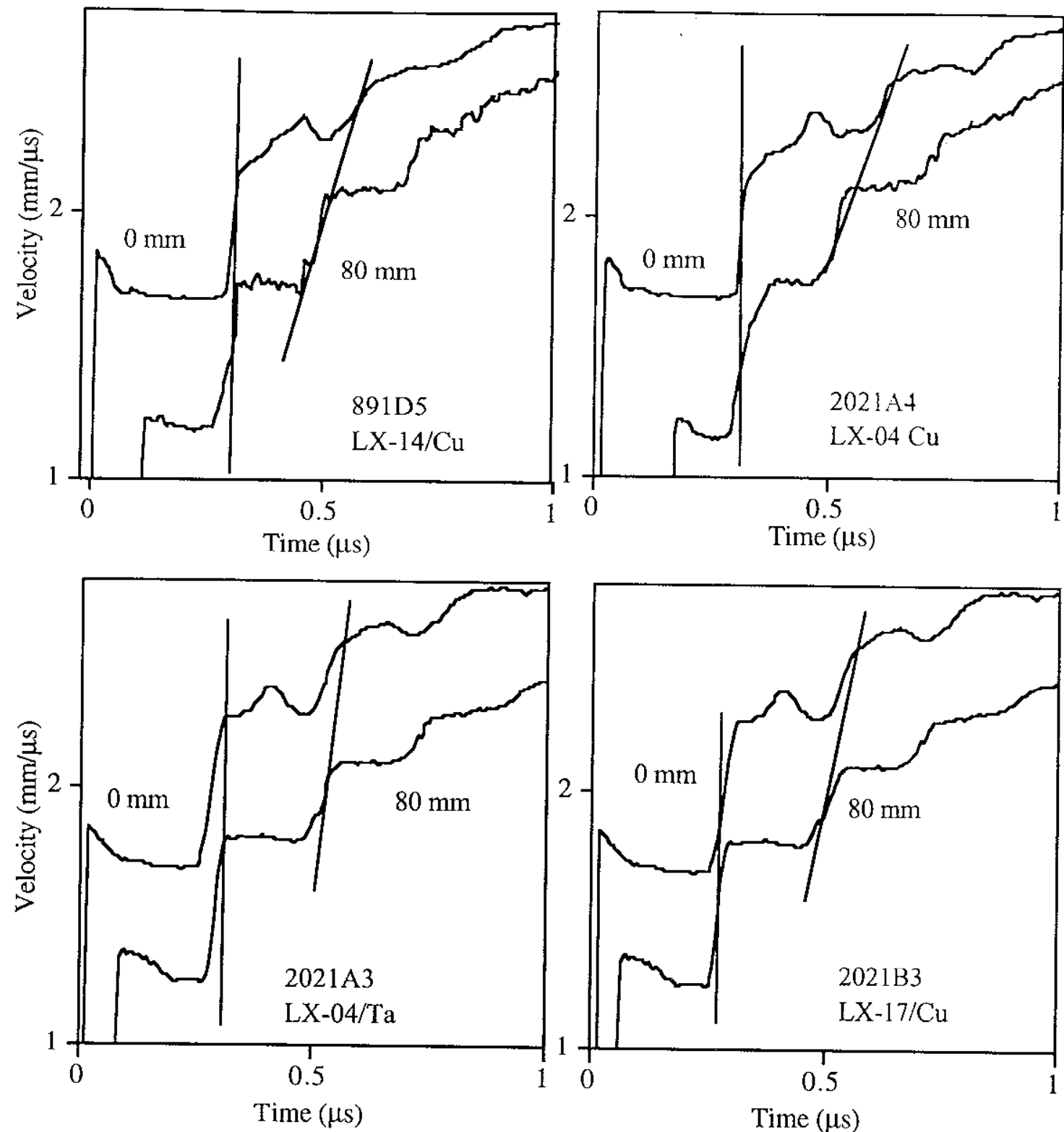

Figure 1. Velocity curves taken on axis $(0 \mathrm{~mm})$ and at $80 \mathrm{~mm}$ for LX-14, LX-04 and LX-17 using copper plates except for tantalum in $2021 \mathrm{~A} 3$. The $80 \mathrm{~mm}$ curves have been moved backwards in time and matched between the first and second plateaus. The presence of spall lengthens the first and second plateaus making comparisons diffuclt even moving curves around in time. 


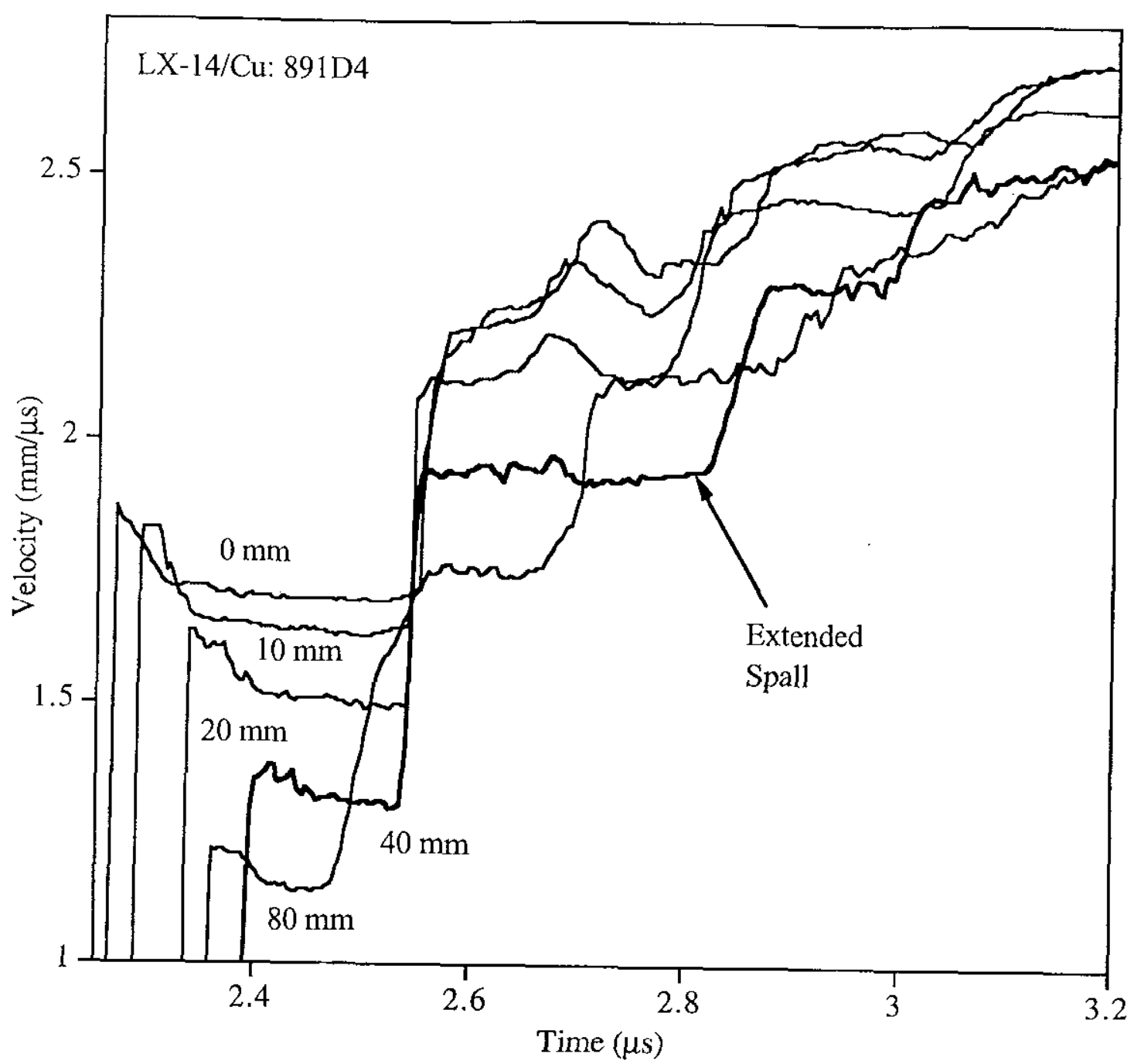

Figure 2. Spall in all five Fabry curves for the worst case, $891 \mathrm{D} 5 \mathrm{LX}-14 / \mathrm{Cu}$. The curves have been moved in time to fit together between the first and second plateaus. The extended second plateau at the $40 \mathrm{~mm}$ position is highlighted. 

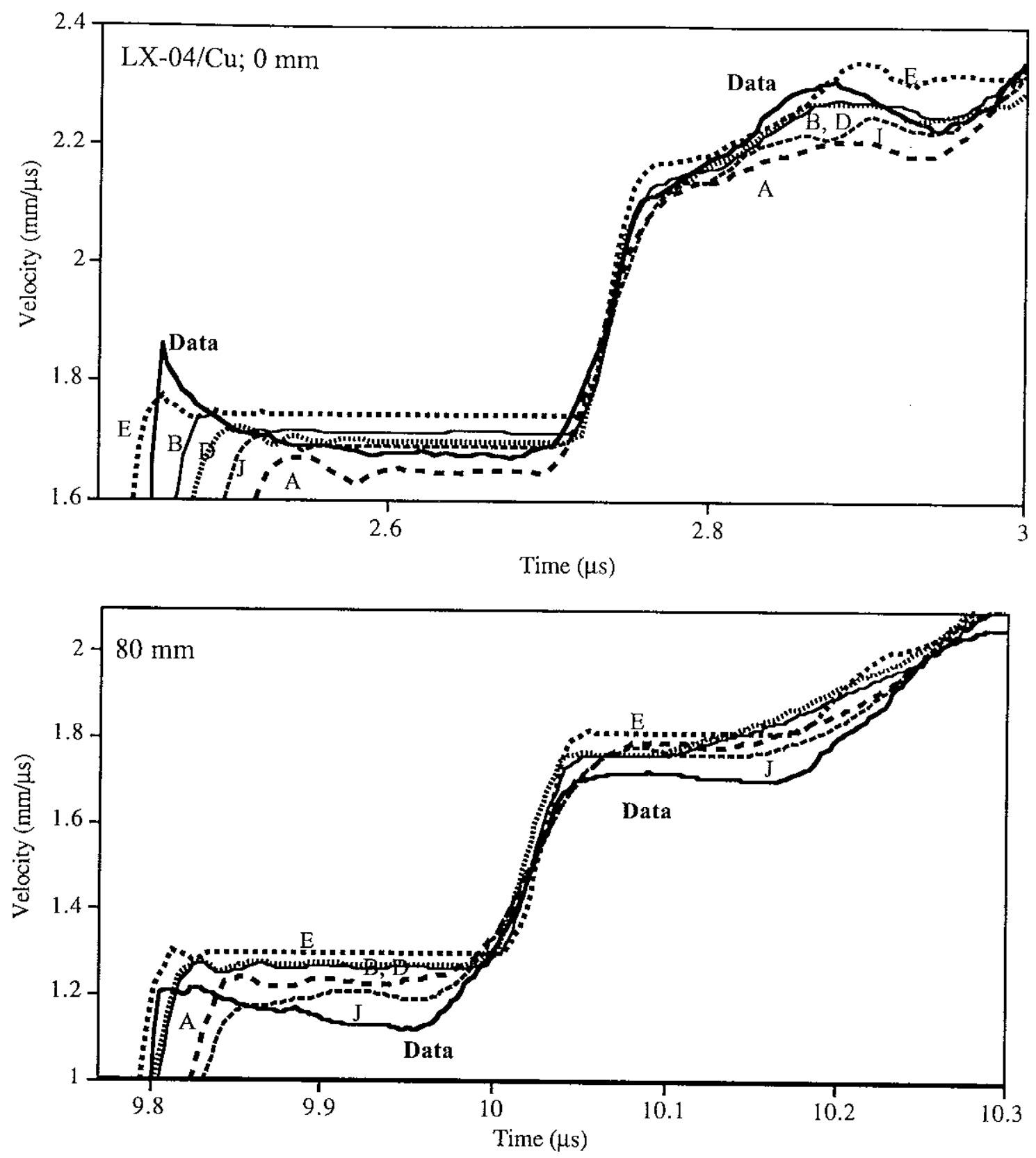

Figure 4. Effect of zoning on the first plateau at 0 and $80 \mathrm{~mm}$ for $\mathrm{LX}-04 / \mathrm{Cu}$. The zones $/ \mathrm{mm}$ for the

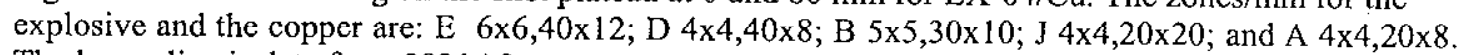
The heavy line is data from 2021A2. 

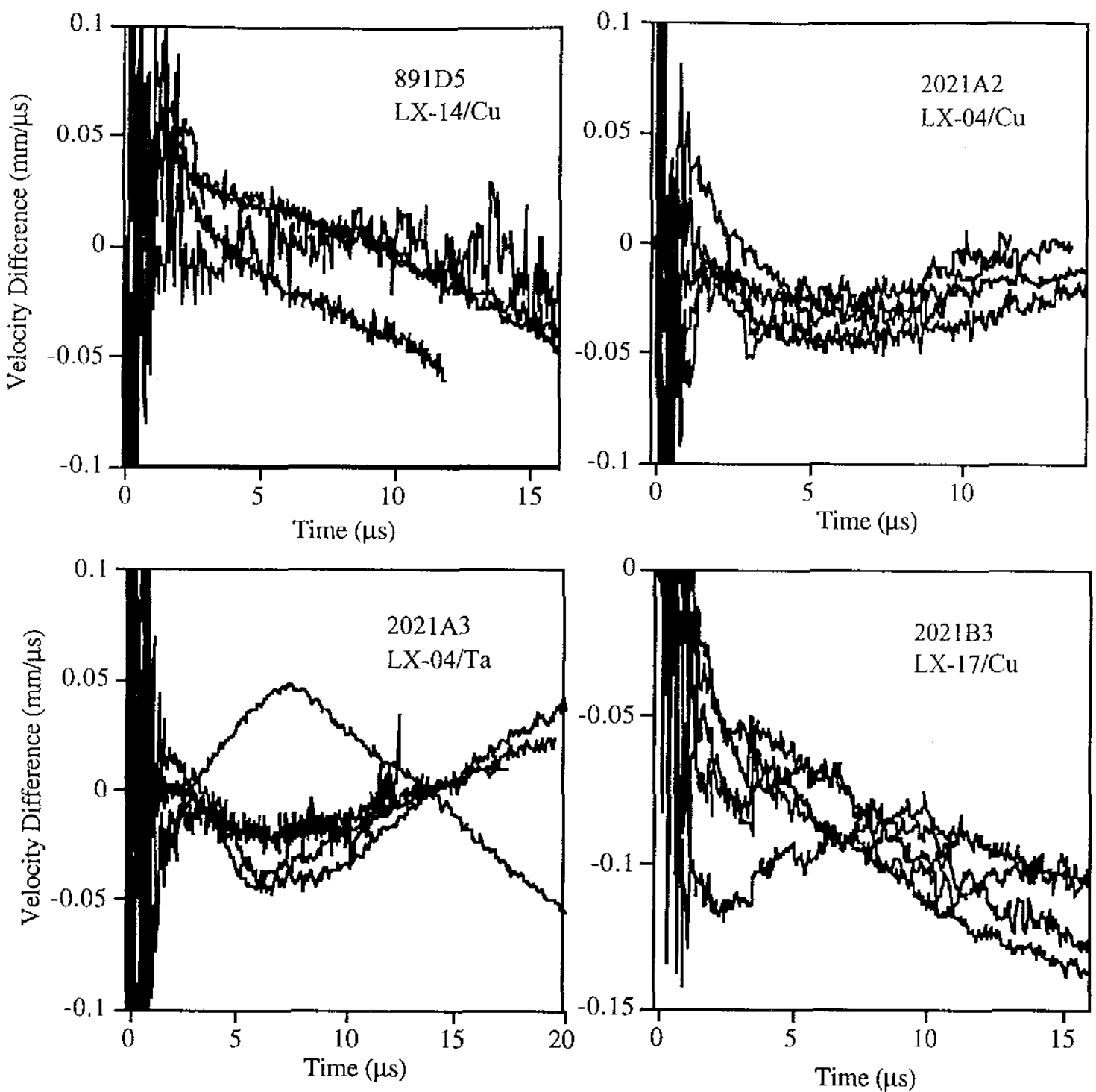

Figure 6. Measured less code velocity differences for four Bigplate shots. The 381 and $A=6.11 \mathrm{JWL}$ 's are within error for LX-14 and LX-04 to long times but the GLO97 JWL in otside of error for LX-17. All five radial positions are shown with the times rezeroed. 
Table 1. Jump-off velocities and first plateau data.

\begin{tabular}{|c|c|c|c|c|c|c|c|c|c|}
\hline \multirow{3}{*}{$\begin{array}{l} \\
\text { Explo- } \\
\text { sive; } \\
\text { Metal }\end{array}$} & \multirow{3}{*}{$\begin{array}{r}\text { Approx. } \\
\text { Density } \\
(\mathrm{g} / \mathrm{cc})\end{array}$} & \multirow[b]{3}{*}{ Fabry No. } & \multicolumn{2}{|c|}{$\begin{array}{c}\text { Radial } \\
\text { Fabry }\end{array}$} & \multicolumn{3}{|c|}{ Jump-Off } & & \multirow{3}{*}{$\begin{array}{c}\text { Velocity } \\
\mathrm{u}_{\mathrm{s}} \\
\left(\mathrm{mm} / \mu_{\mathrm{s}}\right)\end{array}$} \\
\hline & & & \multirow{2}{*}{$\begin{array}{l}\text { dis- } \\
\text { tance } \\
(\mathrm{mm})\end{array}$} & \multirow[b]{2}{*}{$\begin{array}{c}\alpha \\
(\operatorname{deg})\end{array}$} & \multicolumn{3}{|c|}{ in Load Ring Time $(\mu \mathrm{s})$} & \multirow[b]{2}{*}{$\begin{array}{l}\text { Diff- } \\
\text { erence }\end{array}$} & \\
\hline & & & & & $\begin{array}{c}\text { Meas- } \\
\text { ured }\end{array}$ & $\begin{array}{c}\text { Diff- } \\
\text { erence }\end{array}$ & $\begin{array}{c}\text { Expec- } \\
\text { ted }\end{array}$ & & \\
\hline $\mathrm{LX}-14$ & 1.83 & $891 \mathrm{D} 4-1$ & 0 & 0 & 3.271 & 0.00 & 0.00 & & 1.864 \\
\hline \multirow[t]{9}{*}{$\mathrm{Cu}$} & 1.83 & $891 \mathrm{D} 4-2$ & 10 & 27 & 3.550 & 0.28 & 0.27 & 0.01 & 1.840 \\
\hline & 1.83 & 891D4-3 & 20 & 45 & 4.184 & 0.91 & 0.94 & -0.03 & 1.641 \\
\hline & 1.83 & $89104-4$ & 40 & 63 & 6.069 & 2.80 & 2.80 & 0.00 & 1.375 \\
\hline & 1.83 & 891D4-5 & 80 & 76 & 10.390 & 7.12 & 7.09 & 0.03 & 1.222 \\
\hline & 1.80 & $89105-1$ & 0 & 0 & 3.279 & 0.00 & 0.00 & & 1.856 \\
\hline & 1.80 & $891 \mathrm{D} 5-2$ & 10 & 27 & 3.581 & 0.30 & 0.27 & 0.00 & 1.868 \\
\hline & 1.80 & $89105-3$ & 20 & 45 & 4.234 & 0.96 & 0.94 & 0.01 & 1.588 \\
\hline & 1.80 & $89105-4$ & 40 & 63 & 6.214 & 2.94 & 2.80 & 0.14 & 1.261 \\
\hline & 1.80 & 891D5-5 & 80 & 76 & 10.468 & 7.19 & 7.09 & 0.10 & 1.236 \\
\hline LX-04 & 1.87 & $2021 \mathrm{Al}-10$ & 0 & 0 & 3.888 & 0.00 & 0.00 & & 1.830 \\
\hline \multirow[t]{19}{*}{$\mathrm{Cu}$} & 1.87 & $2021 \mathrm{~A} 1-9$ & 10 & 27 & 4.032 & 0.14 & 0.28 & -0.13 & 1.754 \\
\hline & 1.87 & $2021 \mathrm{Al}-8$ & 20 & 45 & 4.674 & 0.79 & 0.98 & -0.19 & 1.650 \\
\hline & 1.87 & $2021 \mathrm{Al}-7$ & 40 & 63 & 6.630 & 2.74 & 2.90 & -0.16 & 1.370 \\
\hline & 1.87 & $2021 \mathrm{~A} 1-6$ & 80 & 76 & 11.230 & 7.34 & 7.35 & -0.01 & 1.155 \\
\hline & 1.87 & $2021 \mathrm{~A} 2-10$ & 0 & 0 & 3.926 & 0.00 & 0.00 & & 1.888 \\
\hline & 1.87 & $2021 \mathrm{~A} 2-9$ & 10 & 27 & 4.252 & 0.33 & 0.28 & 0.05 & 1.771 \\
\hline & 1.87 & $2021 \mathrm{~A} 2-8$ & 20 & 45 & 4.883 & 0.96 & 0.98 & -0.02 & 1.704 \\
\hline & 1.87 & 2021 A $2-7$ & 40 & 63 & 6.835 & 2.91 & 2.90 & 0.01 & 1.387 \\
\hline & 1.87 & $2021 A 2-6$ & 80 & 76 & 11.406 & 7.48 & 7.35 & 0.13 & 1.207 \\
\hline & 1.87 & $2021 \mathrm{~A} 4-10$ & 0 & 0 & 3.900 & 0.00 & 0.00 & & 2.014 \\
\hline & 1.87 & $2021 \mathrm{~A} 4-9$ & 10 & 27 & 4.237 & 0.34 & 0.28 & 0.06 & 1.818 \\
\hline & 1.87 & $2021 \mathrm{~A} 4-8$ & 20 & 45 & 4.853 & 0.95 & 0.98 & -0.02 & 1.624 \\
\hline & 1.87 & $2021 A 4-7$ & 40 & 63 & 6.823 & 2.92 & 2.90 & 0.02 & 1.395 \\
\hline & 1.87 & $2021 \mathrm{~A} 4-6$ & 80 & 76 & 11.369 & 7.47 & 7.35 & 0.12 & 1.192 \\
\hline & 1.87 & $2021 \mathrm{~A} 5-1$ & 0 & 0 & 3.570 & 0.00 & 0.00 & & 1.875 \\
\hline & 1.87 & $2021 \mathrm{~A} 5-2$ & 10 & 27 & 3.869 & 0.30 & 0.28 & 0.02 & 1.749 \\
\hline & 1.87 & 2021 A $5-3$ & 20 & 45 & 4.520 & 0.95 & 0.98 & -0.03 & 1.625 \\
\hline & 1.87 & 2021 A $5-4$ & 40 & 63 & 6.465 & 2.90 & 2.90 & -0.01 & 1.391 \\
\hline & 1.87 & 2021 A $5-5$ & 80 & 76 & 11.049 & 7.48 & 7.35 & 0.13 & 1.195 \\
\hline $\mathrm{LX}-17$ & 1.91 & 2021B2-1 & 0 & 0 & 5.417 & 0.00 & 0.00 & & 1.864 \\
\hline \multirow[t]{4}{*}{$\mathrm{Cu}$} & 1.91 & $2021 \mathrm{~B} 2-2$ & 10 & 17 & 5.637 & 0.22 & 0.20 & 0.02 & 1.823 \\
\hline & 1.91 & $2021 B 2-3$ & 20 & 32 & & & & & \\
\hline & 1.91 & $2021 B 2-4$ & 40 & 51 & 7.983 & 2.57 & 2.52 & 0.05 & 1.526 \\
\hline & 1.91 & 2021B2-5 & 80 & 68 & 12.665 & 7.25 & 7.12 & 0.13 & 1.237 \\
\hline LX-17 & 1.91 & $2021 \mathrm{~B} 3-1$ & 0 & 0 & 6.550 & 0.00 & 0.00 & & 1.853 \\
\hline \multirow[t]{4}{*}{$\mathrm{Cu}$} & 1.91 & $2021 B 3-2$ & 10 & 14 & 6.734 & 0.18 & 0.16 & 0.02 & 1.820 \\
\hline & 1.91 & $2021 B 3-3$ & 20 & 27 & 7.148 & 0.60 & 0.62 & -0.02 & $1.78 \mathrm{I}$ \\
\hline & 1.91 & $2021 B 3-4$ & 40 & 45 & 8.736 & 2.19 & 2.17 & 0.02 & 1.591 \\
\hline & 1.91 & $2021 \mathrm{~B} 3-5$ & 80 & 63 & 13.134 & 6.58 & 6.50 & 0.09 & 1.376 \\
\hline LX-04 & 1.87 & $2021 \mathrm{~A} 3-10$ & 0 & 0 & 3.942 & 0.00 & 0.00 & & 1.400 \\
\hline \multirow[t]{4}{*}{$\mathrm{Ta}$} & 1.87 & $2021 A 3-9$ & 10 & 27 & 4.256 & 0.31 & 0.28 & 0.04 & 1.355 \\
\hline & 1.87 & $2021 \mathrm{~A} 3-8$ & 20 & 45 & 4.900 & 0.96 & 0.98 & -0.02 & 1.348 \\
\hline & 1.87 & $2021 \mathrm{~A} 3-7$ & 40 & 63 & 6.872 & 2.93 & 2.90 & 0.03 & 1.065 \\
\hline & $\begin{array}{l}1.07 \\
1.87\end{array}$ & $2021 \mathrm{~A} 3-6$ & 80 & 76 & 11.393 & 7.45 & 7.35 & 0.10 & 0.915 \\
\hline
\end{tabular}


Table 1, part 2

\begin{tabular}{|c|c|c|c|c|c|c|c|}
\hline \multirow[b]{2}{*}{ Fabry No. } & \multicolumn{3}{|c|}{ First Plateau } & \multicolumn{4}{|c|}{ Second Plateau } \\
\hline & $\begin{array}{c}\text { Mea- } \\
\text { sured } \\
\text { Width } \\
(\mu s)\end{array}$ & $\begin{array}{l}\text { Pullback } \\
\text { Velocity } \\
(\mathrm{mm} / \mu \mathrm{s})\end{array}$ & $\begin{array}{c}\text { Pullback } \\
\text { Velocity } \\
\text { Diff. } \\
(\mathrm{mm} / \mu \mathrm{s})\end{array}$ & $\begin{array}{c}\text { Mea- } \\
\text { sured } \\
\text { Width } \\
(\mu \mathrm{s}) \\
\end{array}$ & $\begin{array}{c}\text { 2nd } \\
\text { Plateau } \\
\text { Height } \\
(\mathrm{mm} / \mu \mathrm{s})\end{array}$ & $\begin{array}{l}\text { Rebound } \\
\text { Velocity } \\
(\mathrm{mm} / \mu \mathrm{s})\end{array}$ & $\begin{array}{c}\text { Rebound } \\
\text { Velocity } \\
\text { Diff. } \\
\text { (mm/ } / \mathrm{s} \text { ) }\end{array}$ \\
\hline $891 \mathrm{D} 4-1$ & 0.287 & 1.690 & -0.174 & 0.25 & 2.10 & 2.42 & 0.32 \\
\hline 891D4-2 & 0.261 & 1.626 & -0.214 & 0.21 & 2.21 & 2.35 & 0.14 \\
\hline $891 \mathrm{D} 4-3$ & 0.209 & 1.486 & -0.155 & 0.20 & 2.11 & 2.21 & 0.10 \\
\hline 891D4-4 & 0.145 & 1.292 & -0.083 & 0.12 & 2.30 & 2.29 & -0.01 \\
\hline 891D4-5 & 0.172 & 1.140 & -0.082 & 0.11 & 1.75 & 1.77 & 0.02 \\
\hline $891 \mathrm{D} 5-1$ & 0.285 & 1.670 & -0.186 & 0.20 & 2.11 & 2.36 & 0.25 \\
\hline $891 D 5-2$ & 0.231 & 1.595 & -0.273 & 0.20 & 2.20 & 2.29 & 0.09 \\
\hline $891 D 5-3$ & 0.217 & 1.455 & -0.133 & 0.18 & 2.07 & 2.15 & 0.08 \\
\hline $891 D 5-4$ & 0.109 & 1.223 & -0.038 & 0.19 & 1.85 & 1.92 & 0.07 \\
\hline 891D5-5 & 0.152 & 1.177 & -0.059 & 0.13 & 1.77 & 1.77 & 0.00 \\
\hline $2021 \mathrm{AI}-10$ & 0.286 & 1.678 & -0.152 & 0.20 & 2.20 & 2.32 & 0.12 \\
\hline $2021 \mathrm{~A} 1-9$ & 0.285 & 1.584 & -0.170 & 0.22 & 2.09 & 2.28 & 0.19 \\
\hline $2021 \mathrm{~A} 1-8$ & 0.283 & 1.463 & -0.187 & 0.15 & 2.04 & 2.15 & 0.11 \\
\hline $2021 \mathrm{~A} 1-7$ & 0.243 & 1.245 & -0.125 & 0.13 & 2.40 & 2.42 & 0.02 \\
\hline $2021 \mathrm{~A} 1-6$ & 0.155 & 1.104 & -0.051 & 0.15 & 1.70 & 1.71 & 0.01 \\
\hline $2021 \mathrm{~A} 2-10$ & 0.245 & 1.672 & -0.216 & 0.20 & 2.11 & 2.31 & 0.20 \\
\hline 2021 A2-9 & 0.257 & 1.586 & -0.185 & 0.20 & 2.12 & 2.24 & 0.12 \\
\hline $2021 A 2-8$ & 0.220 & 1.474 & -0.230 & 0.18 & 2.00 & 2.09 & 0.09 \\
\hline $2021 \mathrm{~A} 2-7$ & 0.220 & 1.253 & -0.134 & 0.15 & 1.85 & 1.88 & 0.03 \\
\hline $2021 \mathrm{~A} 2-6$ & 0.179 & 1.113 & -0.094 & 0.11 & 1.71 & 1.72 & 0.01 \\
\hline $2021 \mathrm{~A} 4-10$ & 0.299 & 1.699 & -0.315 & 0.21 & 2.20 & 2.39 & 0.19 \\
\hline $2021 \mathrm{~A} 4-9$ & 0.274 & 1.606 & -0.212 & 0.21 & 2.12 & 2.28 & 0.16 \\
\hline $2021 \mathrm{~A} 4-8$ & 0.225 & 1.463 & -0.161 & 0.17 & 2.03 & 2.14 & 0.11 \\
\hline 2021A4-7 & 0.196 & 1.265 & -0.130 & 0.17 & 1.88 & 1.89 & 0.01 \\
\hline $2021 \mathrm{~A} 4-6$ & 0.213 & 1.064 & -0.128 & 0.15 & 1.65 & 1.67 & 0.02 \\
\hline $2021 \mathrm{A5}-1$ & 0.271 & 1.697 & -0.178 & 0.19 & 2.22 & 2.37 & 0.15 \\
\hline 2021A5-2 & 0.251 & 1.607 & -0.142 & 0.16 & 2.15 & 2.27 & 0.12 \\
\hline $2021 \mathrm{~A} 5-3$ & 0.245 & 1.474 & -0.151 & 0.18 & 2.03 & 2.13 & 0.10 \\
\hline 2021 A $5-4$ & 0.207 & 1.259 & -0.132 & 1.98 & 1.88 & 1.89 & 0.01 \\
\hline 2021 A5-5 & 0.172 & 1.095 & -0.100 & 0.20 & $1.7 \mathrm{I}$ & 1.70 & -0.01 \\
\hline $2021 \mathrm{~B} 2-1$ & 0.230 & 1.629 & -0.235 & 0.18 & 2.17 & 2.28 & 0.11 \\
\hline $2021 B 2-2$ & 0.243 & 1.594 & -0.229 & 0.21 & 2.11 & 2.30 & 0.19 \\
\hline $2021 \mathrm{~B} 2-3$ & & & & & & & \\
\hline $2021 B 2-4$ & 0.207 & 1.340 & -0.186 & 0.17 & 1.94 & 1.94 & 0.00 \\
\hline $2021 \mathrm{~B} 2-5$ & 0.208 & 1.140 & -0.097 & 0.12 & 1.68 & 1.68 & 0.00 \\
\hline 2021B3-1 & 0.233 & 1.692 & -0.161 & 0.38 & 2.28 & 2.40 & 0.12 \\
\hline $2021 \mathrm{~B} 3-2$ & 0.233 & 1.656 & -0.164 & 0.16 & 2.28 & 2.38 & 0.10 \\
\hline $2021 \mathrm{~B} 3-3$ & 0.227 & 1.599 & -0.182 & 0.19 & 2.20 & 2.30 & 0.10 \\
\hline $2021 \mathrm{~B} 3-4$ & 0.202 & 1.454 & -0.137 & 0.17 & 2.01 & 2.08 & 0.07 \\
\hline $2021 \mathrm{~B} 3-5$ & 0.188 & 1.249 & -0.127 & 0.17 & 1.82 & 1.83 & 0.01 \\
\hline $2021 \mathrm{~A} 3-10$ & 0.300 & 1.135 & -0.265 & 0.19 & 1.57 & 1.69 & 0.12 \\
\hline $2021 \mathrm{~A} 3-9$ & 0.280 & 1.088 & -0.267 & 0.21 & 1.50 & 1.65 & 0.15 \\
\hline $2021 \mathrm{~A} 3-8$ & 0.260 & 0.981 & -0.367 & 0.24 & 1.51 & 1.56 & 0.05 \\
\hline $2021 \mathrm{~A} 3-7$ & 0.230 & 0.837 & -0.228 & 0.22 & 1.45 & 1.42 & -0.03 \\
\hline $2021 \mathrm{~A} 3-6$ & 0.210 & 0.819 & -0.096 & 0.20 & 1.29 & 1.32 & 0.03 \\
\hline
\end{tabular}




\section{Chapter 4. Conclusions}

\section{Bigplate as an EOS Test}

Bigplate, at $\$ 100,000 /$ shot, is too expensive to be used as a new compound EOS test. In fact, the old traditional Cylinder Test has risen to $\$ 40,000 /$ shot and may be replaced by the small 1-D plate shot, Tinyplate. The value of Bigplate is schematically shown in Figure 1.

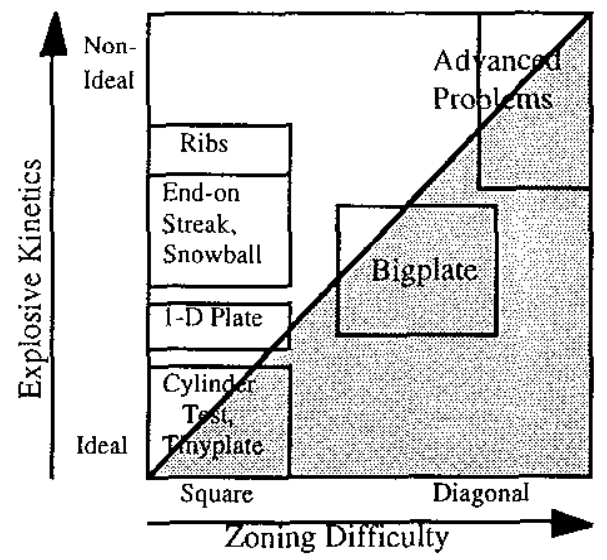

Figure 1. The position of various explosive EOS tests in a space consisting of Explosive Kinetics coupled with Zoning Difficulty. Bigplate lies on the road to complex geometries.

The X-axis consists of zoning difficulty. The easiest tests can be set up with the detonation front running straight into rectangular zones. Even the rib starts this way and then bends around a curve. However, Bigplate has the shock wave crossing zone diagonals virtually everywhere.

The Y-axis describes explosive kinetics: time-dependent explosive detonation. The Cylinder Test, which has a transverse shock wave on copper, shows no reflected wave or metal spall. The spike and kinetics clearly perturb 1-D plate shots to a small degree. The snowball test and the end-on streak camera of a cylinder both see curved shock wave fronts. The rib test shows both curved fronts and the "shadow" velocity, ie. the slowdown of the detonation velocity on the inner curve of the turn. These curved-front tests are all excellent for probing the non-ideality of an explosive, but all have simple zoning.

Bigplate lies between the simple zone tests and the goal of a truly complex geometry with kinetics.

\section{EOS Testing}

The JWL's used in Chapter 3 were wellworn fits to old data and empirically did pretty well. Bigplate is very useful as bench mark for new EOS's such as CHEETAH. A concept can be tried quickly and all one needs are the data files, which now become a standard. Figure 2 shows the result of using the "ideal" LX-17 cylinder $\mathrm{A}=6.73 \mathrm{JWL}$ which was constructed using the same $R_{1}$ and $R_{2}$ that works well for LX-14. The JWL is way low at jump-off because the actual thermochemical C-J pressure of $28 \mathrm{GPa}$ was used, instead of adding in part of the spike pressure as is usually done. At long times, the JWL is also low by 0.10 to 0.15 $\mathrm{mm} / \mu \mathrm{s}$, which previously might not have seemed so bad but is now unacceptable. So this 
is bad fit which is characteristic of the lack of kinetics.

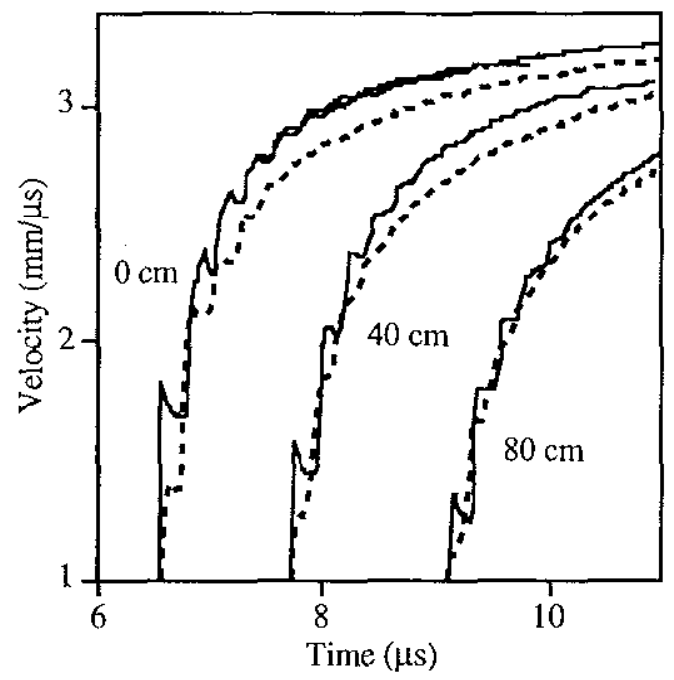

Figure 2. Data (solid lines) and $\mathrm{A}=6.73 \mathrm{JWL}$ (dashed lines) for $\mathrm{LX}-17$ from Bigplate shot 2021B3. The agreement is poor.

A second example is the 1-D CO table for LX-14, which was customized on more complex experiments. The results on axis are shown in Figure 3, where the table results in unacceptable

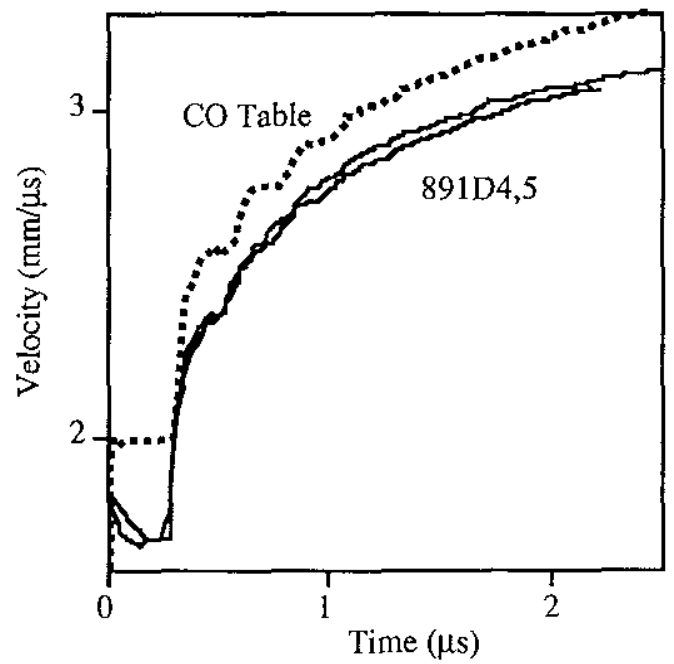

Figure 3. LX-14 $0 \mathrm{~mm}$ data and CO-Table code run showing overshoot. overshoot. Because it was a massaged table for a particular purpose, there is no way to draw conclusions.

\section{Volume of the Test}

One of the appealing properties of the Cylinder test is that the geometric volume of a slice of product gas is very close in volume to the calculated volume. It is not too far off for a plate. We let $\mathrm{R}$ and $\mathrm{X}$ be the initial radius and thickness of the explosive and $h$ the distance the copper moves perpendicular to the initial metal face. We will pretend the plate is 1-D and assume motion outward in every direction. The initial volume of the explosive is $\pi R^{2} X$. The volume later is $\pi(R+2 h)^{2}(X+h)$. The relative volume is the second divided by the first. For $\mathrm{R}$ $=100 \mathrm{~mm}, \mathrm{X}=20 \mathrm{~mm}$ and $\mathrm{h}=25 \mathrm{~mm}$ :

$$
v \approx\left(1+\frac{2 h}{R}\right)^{2}\left(1+\frac{h}{X}\right) \approx 5 .
$$

As seen in Figure 4, this works best on or near the axis.

Bigplate, then, has been taken out to $\mathrm{v} \sim 5$, which is not as far as the standard 6.5 obtained for a Cylinder Test. The cylinder also can be taken to $v \sim 10$ and sometimes even farther to 15-20.

\section{Final Note}

Bigplate was conceived as an explosive EOS test with little or no expected metal spall. The observed spall has proved to be one of the most 
interesting features of the experiment. While not fatal to EOS analysis, the problems of the metal make it all harder. Despite the elegance of the five-beam Fabry, it appears that the future of pure explosive EOS measurements may lie with insitu explosive gauges.

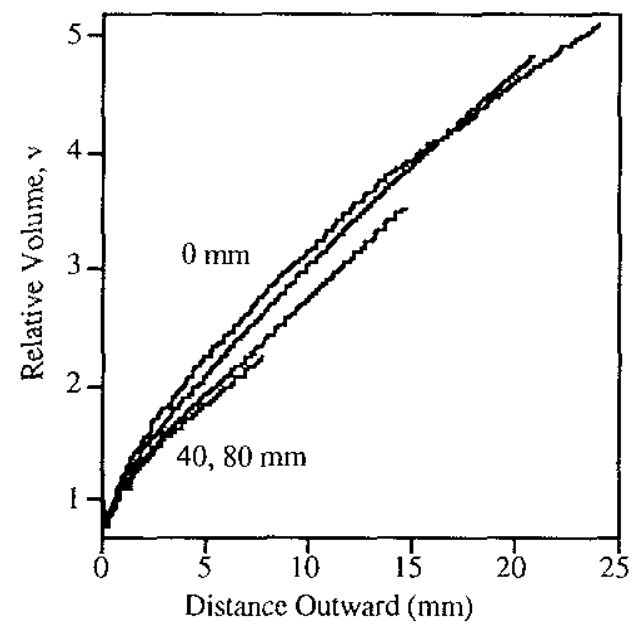

Figure 4. Relative volume vs distance of motion of the copper plate for LX-04. The explosive zone lies 6 zones in (out of 100) from the copper. The curves actually start at different times.

\section{Acknowledgements}

We wish to thank Larry Booth, Don

Breithaupt, Tanda Clauson, Leland Collins, Bret Knapp, Denise Kuklo, Karen Luis, Larry Simmons, Jim Wade, Al Watanabe, Matt Wraith and the Bunker 851 staff for their help in this project. This work was performed under the auspices of the U. S. Department of Energy by the Lawrence Livermore National Laboratory under contract number W-7405-ENG-48. 